\title{
The Archaeological and Genetic Foundations of the European Population during the Late Glacial: Implications for 'Agricultural Thinking'
}

\author{
Clive Gamble, William Davies, Paul Pettitt, \\ Lee Hazelwood \& Martin Richards
}

\begin{abstract}
This article presents the initial results from the S2AGES data base of calibrated radiocarbon estimates from western Europe in the period 25,000-10,000 years ago. Our aim is to present a population history of this sub-continental region by providing a chronologically-secure framework for the interpretation of data from genetics and archaeology. In particular, we define five population events in this period, using dates-as-data, and examine the implications for the archaeology of Late Glacial colonization. We contrast this detailed regional approach to the larger project which we call the cognitive origins synthesis that includes historical linguistics in the reconstruction of population history. We conclude that only archaeology can currently provide the framework for population history and the evaluation of genetic data. Finally, if progress is to be made in the new interdisciplinary field of population history then both disciplines need to refrain from inappropriate agricultural thinking that fosters distorting models of European prehistory, and they should also pay less, if any, attention to historical linguistics.
\end{abstract}

Cognitive archaeology has come a long way from speculative accounts about what went on in the heads of prehistoric people. Conceived as an interdisciplinary scientific approach, based on an empirical methodology (Renfrew \& Zubrow 1994, xiii), it has claimed the archaeological territory of origins and transitions research that interpretive and social approaches to the past have abandoned (Meskell \& Preucell 2004). Cognitive archaeologists have examined the origins of tools (Davidson \& Noble 1993; Wynn 1993) language (Renfrew 1987; 2000), the modern mind (Mithen 1996; Noble \& Davidson 1996; Wynn \& Coolidge 2004), art and symbolism (Lewis-Williams 2003; Renfrew 2001; 2003). Furthermore, the social transition to modern humans (Mellars \& Gibson 1996; Mellars 1996), sedentism (Renfrew 2001), storage (Renfrew \& Scarre 1998) and agriculture (Bar-Yosef 1998; Cauvin 2000) have also attracted their attention as has the 'sapient paradox' which argues the line, championed by Gordon Childe, that it was only with agriculture that we realized our full human potential (Renfrew 1996).
The agenda of cognitive archaeologists has therefore been directed towards big questions and events in the prehistoric human past at a time when concepts such as 'modern humans' (Ingold 2000, ch. 21), style (Boast 1997), ethnicities based on language and culture (Zvelebil 1996; 2002) and the very desirability of origins-focused research (Alexandri 1995; Gamble \& Gittins 2004) are being questioned. What is new about cognitive archaeologists as they pursue traditional archaeological goals is the distinctive, processual approach they have forged from the evidence of historical linguistics, human population genetics and art, in its broadest sense as an indicator of symbolic capacity. For simplicity we refer to this impressive interdisciplinary interweaving as the cognitive origins synthesis that uses these proxy data to achieve its ultimate goal of comparing the ancient and modern mind.

The cognitive origins synthesis frequently uses the global scale to address this comparative goal. For example, when examining the origin and distribution of the language families of the world we learn that, 
Table 1. European population history (Renfrew 2000, 23).

\begin{tabular}{|l|l|}
\hline A & $\begin{array}{l}\text { The first sapiens population episode in the Late } \\
\text { Pleistocene } c .40,000 \text { years ago. }\end{array}$ \\
\hline B & $\begin{array}{l}\text { The retreat to southern refugia during the Late Glacial } \\
\text { Maximum of } c .18,000-15,000 \text { BC. }\end{array}$ \\
\hline C & $\begin{array}{l}\text { The final Pleistocene from } c .15,000 \text { BC and the retreat of } \\
\text { the ice. }\end{array}$ \\
\hline D & $\begin{array}{l}\text { The Holocene from } c .8000 \text { BC prior to the advent of } \\
\text { farming. }\end{array}$ \\
\hline E & The advent of farming during the Holocene. \\
\hline F & $\begin{array}{l}\text { Demographic processes during the Holocene subsequent } \\
\text { to the advent of farming. }\end{array}$ \\
\hline G & The Roman Empire. \\
\hline H & Post-Roman Europe from $c . \mathrm{AD} 400$. \\
\hline
\end{tabular}

'the big question, so far as the Prehistory of Languages is concerned, is the extent to which the linguistic history of the world can be related to world population history' (Renfrew 2000, 23; italics and capitalization original). It is this link in the cognitive origins synthesis between population history, normally reconstructed from extant human genetic variation, and the archaeology of human dispersals that we set out to examine. Our aim is to investigate such claims at a regional rather than global scale and to consider the implications of greater detail and precision for reconstructing population history over fifteen millennia. Furthermore, we deliberately concentrate on a region where Late Glacial population changes did not lead to agriculture. As a result we are able to examine some of the assumptions in the cognitive origins synthesis which have had a significant impact on how archaeologists interpret early prehistory. In this article we address the following questions:

1. What proxy can we use from the archaeological record to track the changing histories of a regional population?

2. What role did climate play in the process of expansion and contraction?

3. How mutually supportive are the links in the cognitive origins synthesis when it is examined with a detailed regional record of population history?

4. What exactly is the explanatory relationship between genetics, archaeology and historical linguistics when we change the focus from global origins questions to an investigation of the process of regional population expansion and contraction?

To answer these questions we present here a regional case study from western Europe and use radiocarbon determinations as a proxy for changes in population history. We are interested in seeing the outcome for the cognitive origins synthesis when instead of glo- bal questions we examine the historically-contingent processes of population contraction and expansion in well-researched landscapes during times of marked climatic change. The advantage of radiocarbon is that, for all its problems of calibration and statistical reliability (Blackwell \& Buck 2003), it nonetheless provides a chronological framework whose precision can be refined within scientific and operational parameters (e.g. Lowe et al. 2001). In the study of population history, a radiocarbon chronology is therefore to be preferred to either the molecular or speaking clock, based respectively on genetic and linguistic evidence.

Renfrew (2000) has usefully identified eight phases in the population history of Europe (Table 1). Our aim is to examine phases B and C with the detail now available from radiocarbon dating.

We will examine these two phases using the S2AGES data base, described below, which contains all available radiocarbon determinations (Gamble et al. 2004; Pettitt et al. 2003) for the region in the period 25-11 ka calibrated radiocarbon years. Using these dates as data for the reconstruction of the timing and scale of population history we will:

- propose a more detailed population history for the Late Glacial of western Europe using radiocarbon determinations;

- assess the role of climate in population expansion and contraction;

- correlate this with estimates of genetic divergence based on the molecular clock;

- assess the contribution of historical linguistics to population history.

\section{Late Glacial population history of western Europe}

A major expansion in human population occurred in western Europe during the Late Glacial (15-11.5 ka cal вг) as the OIS2 ice sheets retreated and unglaciated areas in the north became available for re-settlement. Phylogeographic analysis using molecular-genetic evidence assigns $\sim 60$ per cent of the European mitochondrial DNA (mtDNA) lineages (Richards et al. 2000), and an even higher proportion of West European Y-chromosome lineages (Semino et al. 2000; Rootsi et al. 2004) to a population bottleneck prior to a demic expansion from southwest to northern Europe (Achilli et al. 2004; Torroni et al. 1998; 2001). Molecular clock estimates based on mtDNA variation place this expansion at c. 11-16,000 years. A potential signal of the bottleneck has also been detected in patterns of linkage disequilibrium in the autosomes (Reich et al. 2001).

Population estimates (Bocquet-Appel \& Demars $2000 \mathrm{~b})$, based on the changing distribution of archaeo- 
Box 1. Why a new terminology is needed to study population history.

Archaeological Taxonomic Units were introduced by Robert Foley for the interdisciplinary King's College, Cambridge, Human Diversity Project. Broadly, they form a cultural counterpart to the operational taxonomic unit (OTU) of biology and evolutionary science (Trinkaus 1990). The advantage of such new terminology is that it leaves behind the interpretive baggage that comes with the more familiar archaeological culture, tradition, industry and technocomplex which have never been adequately defined in anthropological terms and remain contentious among archaeologists.

We follow Foley's proposal for ATUs since they allow us to rethink our archaeological classifications (Clarke 1968; Gamble 2001). This is done in order to address the themes of human dispersal and population history and their combined impact on the structure and organization of the material record of past societies. We emphasize these themes in this article (see also Gamble et al. 2004) and the dynamic they produce in the archaeology of small-world populations. Consequently we place the more familiar Palaeolithic topics of diet choice, technological strategy and seasonal settlement movement as secondary.

A fresh terminology requires clarity, and here we disentangle spatial and chronological criteria while leaving open more precise definitions for further exploration - a point we return to in our concluding remarks Section 5. While we focus in this paper on Western Europe, a future goal with the S2AGES data base is to compare population histories between regions with varied traditions of research and nomenclature. To achieve these ends we need some common ground as set out in the following ATU hierarchy (Table 2) and their common equivalents.

Therefore, ATU1s are determined primarily by chronology. With ATU2s chronology plays a major part but is subordinate, as originally proposed by Clarke (1968), to the spatial component. Clarke's terminology was based on levels of affinity between excavated assemblages that recurred in time and space. Cultures had higher levels of affinity than his intermediary classification, the culture-group, while technocomplexes had the least. Affinity depended on the intensity of research with the expectation that more research would produce more archaeological cultures.
Table 2. A provisional hierarchy of Archaeological Taxonomic Units for the study of population history (see Clarke 1968).

\begin{tabular}{|l|l|l|}
\cline { 2 - 3 } \multicolumn{1}{c|}{} & Equivalent & $\begin{array}{l}\text { Examples from Europe and } \\
\text { the Near East }\end{array}$ \\
\hline ATU 1 & Period & $\begin{array}{l}\text { Palaeolithic, Mesolithic, } \\
\text { Neolithic, LUP, } \\
\text { Epipalaeolithic }\end{array}$ \\
\cline { 2 - 3 } & Sub-period & $\begin{array}{l}\text { Early Mesolithic, Late } \\
\text { Epipalaeolithic, Pre-Pottery } \\
\text { Neolithic }\end{array}$ \\
\hline \multirow{2}{*}{ ATU 2 } & $\begin{array}{l}\text { Technocomplex } \\
\text { and culture }\end{array}$ & $\begin{array}{l}\text { Aurignacian, Arched backed } \\
\text { Piece Complex, Magdalenian, } \\
\text { Badegoulian, Solutrean, } \\
\text { Natufian }\end{array}$ \\
\cline { 2 - 3 } & $\begin{array}{l}\text { Culture and } \\
\text { industry }\end{array}$ & $\begin{array}{l}\text { Upper Magdalenian, Late } \\
\text { Natufian, PPNB, Final } \\
\text { Creswellian }\end{array}$ \\
\cline { 2 - 3 } & $\begin{array}{l}\text { Industry and } \\
\text { assemblage }\end{array}$ & $\begin{array}{l}\text { Perigordian Vc, Magdalenian } \\
\text { IV, Lower Epigravettian with } \\
\text { shouldered points }\end{array}$ \\
\hline ATU 3 & $\begin{array}{l}\text { Artefacts and } \\
\text { type fossils }\end{array}$ & $\begin{array}{l}\text { Zinken, navettes, Mouilah } \\
\text { points, lignite figurine, fox } \\
\text { canine pendant }\end{array}$ \\
\cline { 2 - 3 } & $\begin{array}{l}\text { Scalar retouch, cut marks on } \\
\text { animal bones, truncation, } \\
\text { post-hole depth }\end{array}$ \\
\hline \multirow{2}{*}{$\begin{array}{l}\text { Attribute } \\
\text { and }\end{array}$} \\
\cline { 2 - 3 }
\end{tabular}

However, affinity means different things to different archaeologists. Consequently a great deal of time can be spent debating whether an archaeological entity is a technocomplex or a culture, a tradition or an industry (Table 2). For present purposes we have therefore blurred these distinctions in order to emphasize that ATU2s primarily assist the historical investigation of the spatial organization of human populations. Demography rather than culture is the purpose of this classificatory system. Further refinement of the ATU system will need to take into account the spatial scales in these demographic processes.

Finally, at the base of the hierarchy are ATU3s, artefacts and attributes, which are determined by space; for example, the position of the retouch on a bladelet that forms a recurrent type. Their chronological significance only emerges through further, and repeated associations among ATU2s. logical sites, indicate an increase in the population of western Europe (excluding Iberia) from 9000 to 40,000 persons with the corresponding areas occupied aug- mented from $0.55 \mathrm{Mkm}^{2}$ to $1.12 \mathrm{Mkm}^{2}$. In the rest of this article we refer to this overall population as the metapopulation. The demic expansion is associated 


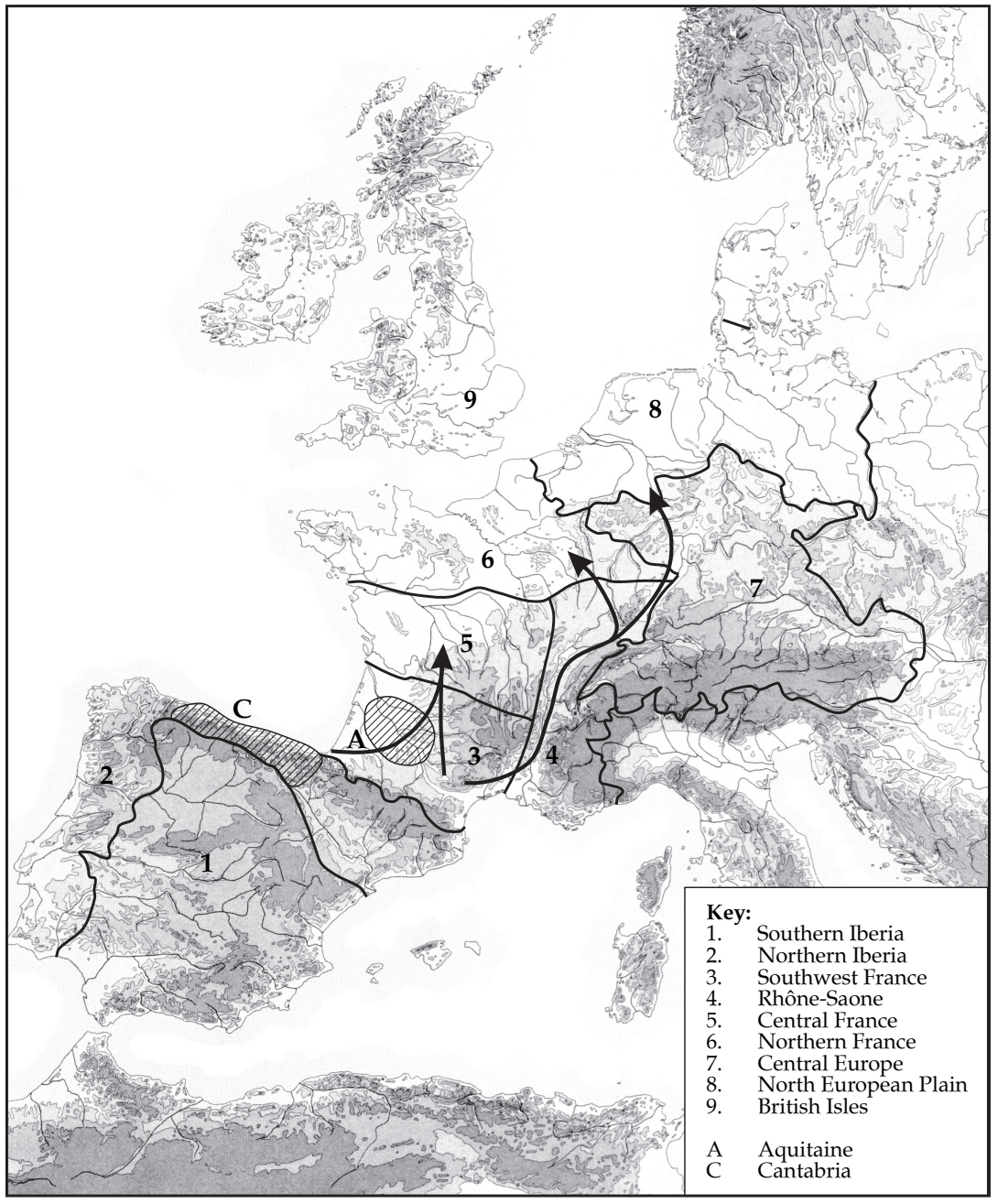

Figure 1. Late Glacial Western Europe showing sampling regions, the two geographical refugia and probable expansion routes.

with the Magdalenian, a time-space archaeological taxonomic unit (ATU), which is found in western Europe from c. 22 to $13 \mathrm{ka}$ cal BP and is known for its abundant cave and mobiliary art.

A new terminology (Box 1) reminds us that the simple mapping of linguistic families or genetic lineages onto traditional archaeological cultures often yields unsatisfactory results because, as Zvelebil (2002) points out, 'it is difficult to identify which, if any of such elements specify population's ethnic sense of belonging in its historically situated context'. For example, the temporal sub-divisions of the Magdalenian ATU2, based on artefact-type fossils and stratigraphic sequences, as well as the degree to which Magdalenian Europe was culturally homogeneous or heterogeneous, remain problematic (Laville et al. 1980; Thévenin 1995). These sub-divisions of a culture-history approach, however, were never directed towards understanding either population or linguistic history. If we rely on them alone as markers of such processes, then the timing, direction and pattern of the Late Glacial population expansion will remain imprecise.

\section{S2AGES data base}

To address these issues, and to examine the correspondence between archaeological and molecular evidence for demic expansion, we present here the first results from S2AGES, a data base of OIS2 radiocarbon determinations from Europe, the Near East and North Africa (Pettitt et al. 2003). The sub-sample described here comprises 2255 determinations from 1200 archaeological assemblages in western Europe (Fig. 1).

Figure 2 presents, using CALPAL (Weninger \& Jöris 2000), the calibrated radiocarbon determinations for Iberia, France and northern Europe. These are compared to the GRIP $\delta^{18}$ curve which is the basis of the Late Glacial stratotype (Björck et al. 1998).

CALPAL was selected for calibrating the radiocarbon dates for two main reasons: (a) it uses more data points beyond Heinrich event 1 than does the currently-available INTCAL98 calibration curve; and (b) it uniquely allows graphical comparison of the calibrated output with environmental proxy curves. Both the uncalibrated and calibrated radiometric dates are given in the S2AGES data base, allowing other users to apply their own preferred calibration programmes during its useful lifetime, doubtless employing more precise calibration curves as they become available. We use CALPAL here as a falsifiable model. Many of the CALPAL output graphs present summed relative probabilities of dates, creating some problems of comparability between dates at the inter- and intra-site scales (Davies et al. in prep.). Auditing of the data base for methodological and archaeological quality of the dates (Davies et al. in prep.) was completed too late for inclusion in this article. Some two-thirds of the 6000 dates in our data base have been excluded from further analyses, as we cannot be confident of their methodological and archaeological validity. Using the validated dates 
alone, it should be easier to express our confidence in what the curves appear to be saying with regard to human population responses to climate change. Here, however, we present some general trends to initiate discussion.

Figures 2-6 essentially describe the densities of calibrated dates, with the small vertical bars along the x-axes (shown in Figs. $3 \&$ 6) representing the calibrated median values of individual age determinations, and the frequency curves the summed relative probabilities (taking the calibrated one sigma values into account). We advise that readers interpret these figures in broad terms, looking for the major troughs and peaks in the frequency distribution, representing proxy falls and rises in human activity and/or population respectively.

Extensive use of CALPAL was made by the Stage Three Project (van Andel \& Davies 2003) for the Middle and earlier part of the Upper Palaeolithic (60-25 ka), covering Renfrew's population phase A (Table 1). That project concluded that the first Homo sapiens population episode in Europe (c. $45 \mathrm{ka}$ ), while of significance in behavioural innovation, was exceeded in elaboration by the social systems employed by later Homo sapiens groups from about 30-20 ka (the Gravettian) (Davies et al. 2003). The S2AGES data base is a development of the organizational characteristics utilized in the Stage Three Project, both being designed primarily to document spatio-temporal variations in the density of human occupation, from which patterns can be inferred inductively and tested against the archaeological evidence itself.

We interpret the changing frequencies of calibrated determinations in Figure 1 as a proxy for the timing and direction of demic expansion as well as relative levels of human activity between regions. This method, using dates-as-data, is an established technique to investigate a process such as population dispersal into unoccupied habitats (Blackwell \& Buck 2003; Holdaway \& Porch 1995; Housley et al. 1997; Lourandos \& David 2002; Rick 1987; Ross 2001; van Andel et al. 2003).

On this basis we recognize five major population events for Late Glacial western Europe (Tables 3 $\& 4$ ), discussed in detail below. We define population events as discrete and definable trends in the proxy data, from which we infer significant changes in the number and/or distribution of human populations. The divisions refer to our assessment of significant changes in radiocarbon date frequency for the data from France and northern Europe. Iberia provides a more complicated signature which we argue below stems from its position as a southern refuge.
It might be argued that the changing frequencies of determinations in areas north of the European continental divide reflect nothing more than the frequency with which archaeologists send samples for radiocarbon dating. Some stratified assemblages may have multiple radiocarbon samples while others are represented by only a single date. Moreover, it might be claimed that traditions of research differ between the countries in our sample thereby introducing another distortion. Such variation is to be expected in data collected over the past 40 years and, for the most part, to answer questions other than those relating to demic expansion and contraction.

But this collection strategy is a sampling advantage. The S2AGES data base is a grab sample of what could have been recovered for dating. Unlike the samples selected to investigate an origins question, such as the appearance of modern humans, the dates in the S2AGES data base are not biased by selective sampling towards any particular model of population history; for example by focusing the dating effort on moments in the sequence which archaeologists, for whatever reason, regard as more important than others. Confirmation can be found in Table 5 where we see very similar results for France and northern Europe in terms of the mean number of dates per assemblage. The large sample size in the data base is therefore our strongest argument for a dates-as-data approach although we recognize that more auditing and modelling of this issue needs to be undertaken (Davies et al. in prep.; Pettitt et al. 2003; van Andel et al. 2003).

Table 3 is based upon chronometric data only. It can, of course, be expanded further using the archaeological evidence for settlement patterns, estimates of occupational intensity, inter-regional contacts and measures of complexity and diversity in the composition of ATUs at a variety of scales. The predictions offered in Table 6 address the issue of how we would introduce the complexities of the archaeological record into a wider synthesis of Late Glacial population history. The predictions cannot be tested with radiometric data alone but need to bring into play the patterning in the archaeological data that is visible at several interlocking ATU scales; as well as the more familiar spatial hierarchy of site/locale, region and sub-continental drainage basins (Gamble 1986). In particular, the clarity of the $\mathrm{H} 2$ predictions are especially susceptible to obfuscation from scalar changes. While any differences between $\mathrm{H} 1$ and $\mathrm{H} 2$ might appear to be fuzzy or even non-existent, the underlying assumption behind $\mathrm{H} 2$ can be tested only with reference to the changes in the nature of the archaeological record 
Gamble et al.

Table 3. Late Glacial population history of Western Europe as reconstructed from archaeological, radiocarbon and molecular evidence. The GRIP stratotype (see Fig. 2) after Björck et al. (1998) and Walker et al. (1999).

\begin{tabular}{|l|l|l|l|l|l|}
\hline Population event & Settlement pattern & Dominant settlement type & Phylogeography & $\begin{array}{l}\text { GRIP } \\
\text { Stratotype }\end{array}$ & $\begin{array}{l}\text { GRIP Ice- } \\
\text { core years BP }\end{array}$ \\
\hline 1. Refugium & Dispersed & Rockshelter & Low population size & LGM-GS-2c & 25-19.5 ka \\
\hline 2. Initial demic expansion & Pioneer & Rockshelter and Open & Low population size & GS-2b-GS-2a & $19.5-16 \mathrm{ka}$ \\
\hline $\begin{array}{l}\text { 3.1. Main demic expansion } \\
\text { 3.2. Main demic expansion }\end{array}$ & $\begin{array}{l}\text { Residential } \\
\text { Residential }\end{array}$ & $\begin{array}{l}\text { Rockshelter } \\
\text { Open }\end{array}$ & $\begin{array}{l}\text { Founder effect and } \\
\text { expansion }\end{array}$ & $\begin{array}{l}\text { GS-2a } \\
\text { GI-1e }\end{array}$ & $\begin{array}{l}16-14.7 \mathrm{ka} \\
14.7-14 \mathrm{ka}\end{array}$ \\
\hline $\begin{array}{l}\text { 4. Population stasis } \\
\text { 5ucleation }\end{array}$ & Open & $\begin{array}{l}\text { Founder effect and } \\
\text { expansion }\end{array}$ & GI-1d-GI-1a & $14-12.9 \mathrm{ka}$ \\
\hline 5opulation contraction & & Open & & GS1 & $12.9-11.5 \mathrm{ka}$ \\
\hline
\end{tabular}

Table 4. A chronology for the population history of Late Glacial Western Europe.

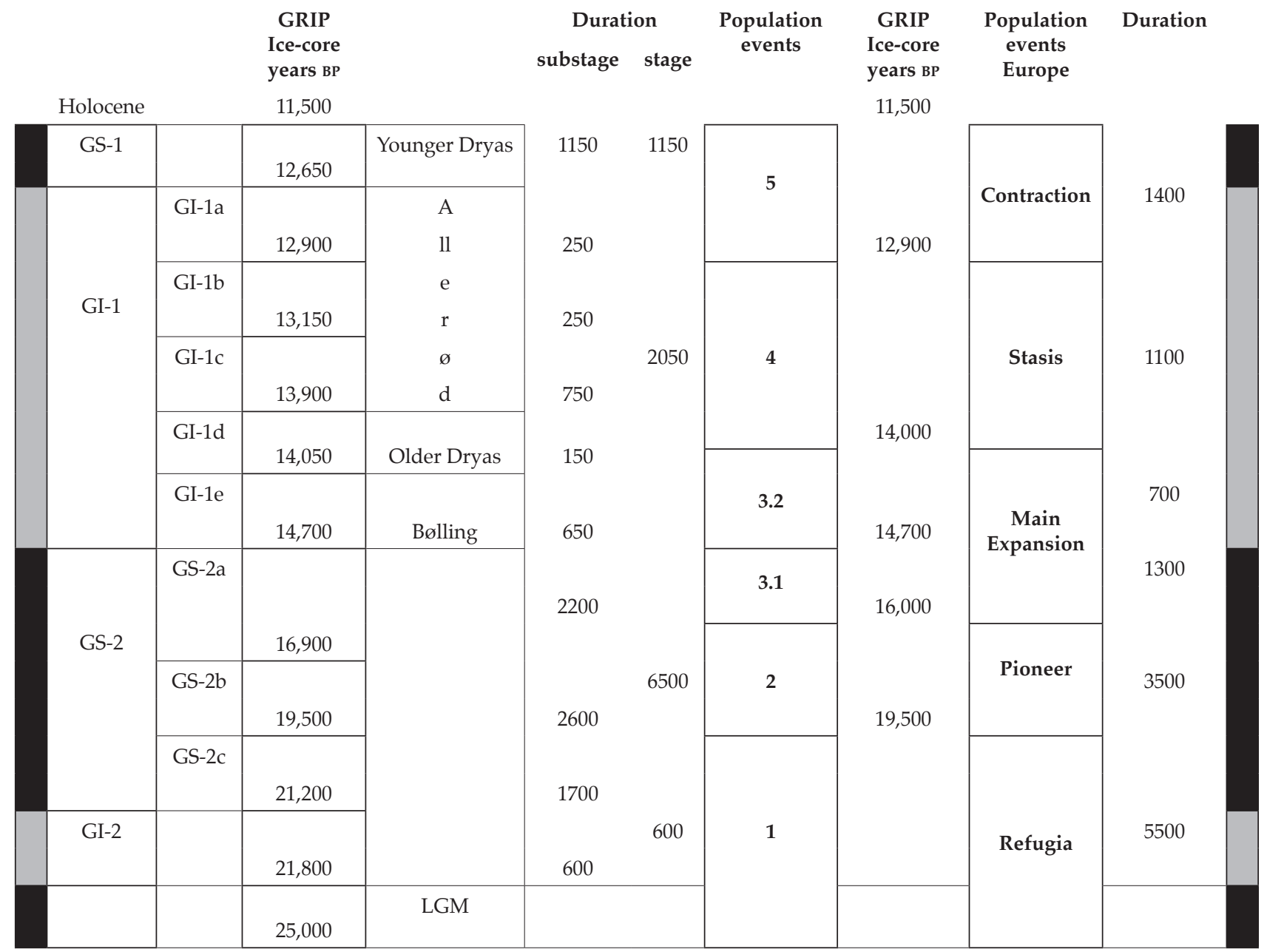

itself: diversity of tool types, and in the variability of assemblages at the intra- and inter-site scales.

\section{Refugia models for regional population history}

The Late Glacial re-population of Europe has depended upon biological concepts of refugia and dispersal corridors (Tchernov 1992; Vrba 1988; Willis et al. 2004; Willis \& Whittaker 2000). It is the refugium model which mostly concerns us here.

Dolukhanov (1979; Fig. 1) drew attention to a western and eastern refuge and their influence on the repopulation of central Europe during the Allerød 
interstadial. More recently the western refuge has been examined from an ecological perspective (Eriksen 1996; Jochim 1983; 1987; Jochim et al. 1999; Rensink 1993) and at a variety of ATU2 scales (Barton et al. 2003; Charles 1996; Otte 1997; Straus 2000a), while Ross (2001), following Soffer's (1987) earlier study, has analyzed the eastern refuge using dates-as-data with a GIS methodology. A recent summary of the perceived cultural differences between the two refugia is provided by Djindjian et al. (1999), while geographical route-ways in Europe which likely served as major dispersal corridors have also been mapped (Djindjian 1994). Zvelebil (2001; Fig. 1) has provided a valuable political context for such concepts by re-visiting Indreko's (1948) model which postulated a western homeland (refuge) from which Finno-Ugrian speakers dispersed.

Housley (et al. 1997) put forward a two-stage model of settlement, pioneer and residential, during re-colonization. This settlement sequence was based on relatively slow rates of population expansion into formerly periglacial environments. These estimates have been questioned (Barton et al. 2003; Blockley et al. 2000), and a more rapid process suggested that would make such temporal settlement distinctions difficult to detect. The model does, however, provide a spur to greater chronological precision as well as challenging some traditional views about the temporal, cultural and technological relationships among the ATU2s of the Late Glacial.

The pattern of human dispersal during population expansion is currently modelled archaeologically as either a string of pearls, where successive population units bud off but maintain close contact, or a leap-frog pattern where the same units move to patches of preferred resources and contiguity is lost (Anderson \& Gillam 2000; Moore 2001; van Andel \& Runnels 1995). Behind both patterns stands the classic wave-of-advance model (Ammerman \& Cavalli-Sforza 1973; 1979) that is still the most influential account of population history based on the combination of dates-as-data and human genetic evidence. Subsequent reaction to the wave-of-advance model has questioned the evidence for population advance on such a broad front (Zvelebil 1986) and simulation studies point to the moderating effects of geography and resources on the shape and speed of the travelling wave (Steele et al. 1998). It can also be shown (Hazelwood \& Steele 2004, 677) that the Fisher-Skellam equation determines the width and speed of the travelling wave by population-averaged reproductive and dispersal rates.

The apparent inconsistencies between the waveof-advance model and archaeological evidence for dispersal have recently been addressed in detail by Hazelwood \& Steele (2004). Their model indicates that the scale of geographical resources, population growth and dispersal characteristics affect the resolution with which archaeological data illustrate the travelling wave process. Therefore, absence of a clear signature for the refugia and recolonization hypothesis would not be entirely unexpected, especially when the travelling waves were shallow and relatively fast as was the case for human dispersal into North America from Beringia (Hazelwood \& Steele 2004, 677-8). The result has been to 'wash out' any spatial gradient in the radiocarbon dates that might indicate initial peopling. By contrast, the travelling wave described by Ammerman \& Cavalli-Sforza (1973) for the Neolithic expansion in Europe was steep and relatively slow, and as a result a clear geographical direction is indicated in the radiocarbon data. In the study presented here, climate changed slowly in comparison to the intrinsic dispersal rates expected for mobile huntergatherers. This provides us with the opportunity to detect hunter-gatherer population movements when normally these cannot be resolved.

\section{Two different refugia}

The S2AGES data base allows us to examine some of these concepts by bringing to them a greater degree 
Table 6. Predicted patterning in settlement histories from the radiocarbon evidence.

\begin{tabular}{|l|l|l|}
\hline GRIP chronology & H1 & H2 \\
\hline $\begin{array}{l}\text { GS-2a date rise } \\
\text { Cold phase) }\end{array}$ & $\begin{array}{l}\text { Population } \\
\text { increase in the } \\
\text { region (through } \\
\text { growth and/or } \\
\text { immigration) }\end{array}$ & $\begin{array}{l}\text { Expansion and } \\
\text { intensification of } \\
\text { activity in the region, } \\
\text { perhaps reflecting a } \\
\text { population increase } \\
\text { (through growth and } \\
\text { or immigration) }\end{array}$ \\
\hline $\begin{array}{l}\text { GI-1 date decline } \\
\text { (Warm phase) }\end{array}$ & $\begin{array}{l}\text { Population } \\
\text { decline in } \\
\text { the region } \\
\text { (extinction or } \\
\text { out-migration) }\end{array}$ & $\begin{array}{l}\text { Retrenchment and } \\
\text { re-organization in } \\
\text { settlement pattern } \\
\text { at the regional scale, } \\
\text { perhaps resulting in an } \\
\text { increase in aggregation } \\
\text { sites. Some population } \\
\text { decline possible }\end{array}$ \\
\hline $\begin{array}{l}\text { GS-1 date } \\
\text { trough' (Younger } \\
\text { Dryas cold phase) }\end{array}$ & $\begin{array}{l}\text { Population } \\
\text { stasis/refuge }\end{array}$ & $\begin{array}{l}\text { No change in } \\
\text { occupation densities } \\
\text { (although site spatio- } \\
\text { temporal distributions } \\
\text { or settlement patterns } \\
\text { might well change) }\end{array}$ \\
\hline
\end{tabular}

$\mathrm{H} 1$ = date frequencies directly equivalent to population levels $\mathrm{H} 2$ = date frequencies reflecting changes in occupation density

of chronological precision. For our present purposes we need to expand the concept of refugium which we use here in two senses to describe:

1. the G refugium; the minimum geographical distribution of population, irrespective of population size;

2. the $\mathrm{M}$ refugium; the minimum size of the metapopulation, irrespective of geographic extent.

The utility of distinguishing two refugia can be illustrated by Terberger and Street's demonstration of human occupation on the Rhine at a time when this area was thought to be de-populated (Street \& Terberger 1999; 2002; Housley et al. 1997). While such finds are still isolated and the majority of contemporary occupation is still to be found in Cantabria and southwest France (see below), their observation points to the problems in accurately specifying the geographical limits of a refuge. Indeed, precise definition seems to us counterproductive. The $\mathrm{G}$ and $\mathrm{M}$ refugia also question existing models for western Europe. These predict that the lowest metapopulation and the smallest inhabited area coincided with the last glacial maximum (= LGM 25-21.8 ka вP) (Soffer \& Gamble 1990; Straus 2000a). Archaeological evidence, as we have seen, is already contradicting this assessment. Furthermore, the length of the LGM is poorly defined. Ross (2001) shows for central Europe that the minimum values for archaeological sites occurred later, during GS-2b;
Table 7. Two biogeographical definitions (Vrba 1988, 408).

Distribution drift: changes in species' geographic distributions, including shrinkage/fragmentation (vicariance) and expansion/coalescence (mobilism).

Refugium: An area that, over a given time interval, escapes major climatic changes typical of a region as a whole, and in which a biome persists that has disappeared elsewhere.

while Davies \& Gollop (2003), using radiocarbon determinations, emphasize just how small populations must have been in the preceding OIS3. The expansion of population in GS-2a, a cold phase, is therefore noteworthy within the context of the Upper Pleistocene as well as the Late Glacial.

A more sensitive model is provided by Vrba (1988) in her discussion of distribution drift and refugium (Table 7) as mechanisms by which lineages cope with habitat fluctuation. Distribution drift is particularly pertinent in the Rhineland example (Terberger \& Street 2002) in indicating the scale at which human hunting societies coped with climatic perturbations such as those in the Late Glacial. Humans are extensive users of space such that the size of the metapopulation may be far lower than implied by the size of the territory being utilized. The problems of estimating hunter-gatherer population density are well known (Binford 2001) and result from mobility and the construction by individuals of networks which vary by context (Gamble 1999).

Where the definition of the Late Glacial G refugium can be tightened lies in determining whether richness or constancy formed its principal biotic feature. The former was favoured by both Jochim (1987) and Soffer (1987). Resource richness provided a population-pull that led to in-migration and population increase in both the western and eastern G refugia. Population-push out of the $\mathrm{G}$ refugium therefore occurred as northern environments recovered from glaciation and resources started to exert a pull. The resource richness model led Jochim $(1983,219)$ to an ecological explanation for the geographical distribution of the Franco-Cantabrian cave art. He argued that in a context of population growth within the refuge the rituals that the art served helped to demarcate territories for key resources such as salmon.

By contrast, Vrba (1988) determines the advantage of a refugium to a species by the constancy that it offers in their normal habitat (see Gamble et al. 2004). In our opinion constancy is more amenable to measurement through the indirect proxies of the palaeoenvironmental record since it can be translated into hominin tolerance and preference (Davies \& Gollop 2003). 
The historical metapopulation is therefore difficult to estimate from the spatial extent of settlement in a region the size of western Europe. For these reasons we follow Bocquet-Appel \& Demars (2000b) who provide an estimate of the refugium metapopulation in France of 9000 persons, with the majority of these in the Aquitaine region. For reasons already discussed, we see such a metapopulation covering a much larger, albeit intermittent and infrequent, diaspora. Furthermore, the $\mathrm{M}$ refugium of western Europe needs to include the population in Iberia. Applying their methodology to this area results in an $\mathrm{M}$ refugium with some 17,000 persons (Gamble et al. 2004; Table 6) which expanded to some 64,000 in the initial stages of northward expansion (Gamble et al. 2004) in western Europe. As we discuss below, the changing size of the metapopulation is less important for our understanding of the genetic history of western Europe and more so for the social environment where cultural transmission took place (Shennan 2002).

Population event 1: refugium, 25-19.5 ka вР

Iberia, with radiocarbon determinations predominantly from Cantabria and Portugal (Straus et al. 2000a), was the major $G$ refugium into which population contracted throughout the LGM and remained until GS-2b (Fig. 2). By contrast, human presence was markedly lower in France during this long period even though the southwest, Aquitaine, has often been proposed as a major $\mathrm{G}$ refugium (Demars 1996; Jochim 1987; Soffer \& Gamble 1990). North central Europe was never entirely abandoned as shown for example by the site of Wiesbaden-Igstadt dated to GI-2 in the Rhineland (Terberger \& Street 2002) but the calibrated curve indicates a low, probably intermittent, human presence in this region.

When the duration of the $\mathrm{M}$ refugium is examined, using the S2AGES data, we find it lasted much longer than the LGM, sensu stricto and continued into GS- $2 b$. Moreover, a radiocarbon data base compiled for the Stage 3 project (van Andel et al. 2003) shows very low human presence in north central Europe for at least the $10 \mathrm{ka}$ preceding the LGM in spite of a further six brief interstadials in this time interval (Walker et al. 1999).

The Solutrean has been proposed as the ATU2 of the LGM refugium (Straus 2000b; Fig. 3). The typological differences between the Solutrean and Badegoulian (or Early Magdalenian) ATU2s are regarded by archaeologists as too great to derive the latter from the former (Djindjian et al. 1999). As recently pointed out by Terberger \& Street (2002) the Badegoulian is most closely related to ATU2s in central and eastern rather

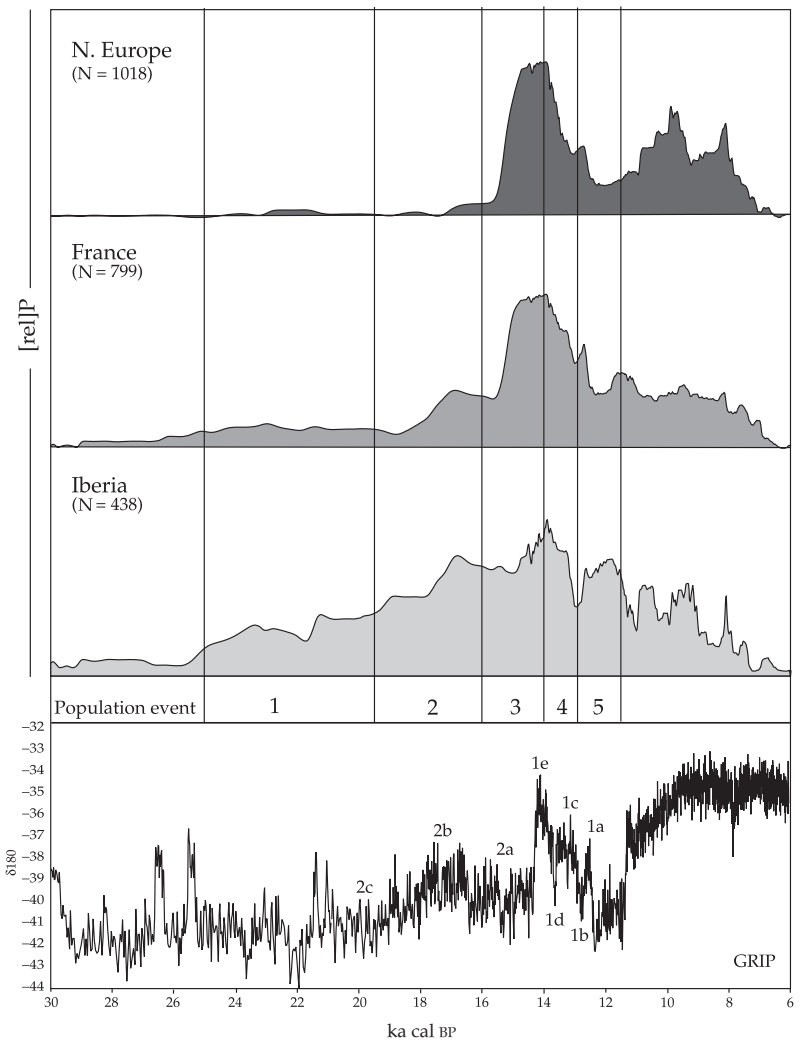

Figure 2. Overview of Late Glacial radiocarbon dating probabilities for archaeological sites and assemblages. The determinations are calibrated using CALPAL (Weninger \& Jöris 2000) and presented by major region. The five population events (Tables $3 \& 4$ ) are indicated. The GRIP $\delta^{18}$ climate curve provides the stratotype for the Late Glacial-Last Termination event based stratigraphy (Björck et al. 1998; Walker et al. 1999). This recognizes, after the Last Glacial maximum (LGM), two warm events (Greenland Interstadials 1 and 2) and two cold events (Greenland stadials 1 \& 2). Currently GS-2 is subdivided into three sub-stages and GI-1 into five, shown here. In conventional terms GS-1 broadly corresponds to the Younger Dryas, GI-1e to the Bølling and GI-1c-1a to the Allered interstadials. Stratotype boundaries in GRIP ice core years are as follows.

$$
\begin{aligned}
& G I-2=21.8-21.2 \mathrm{ka} \\
& G S-2=21.2-14.7 \mathrm{ka} \\
& G I-1=14.7-12.7 \mathrm{ka} \\
& G S-1=12.7-11.5 \mathrm{ka}
\end{aligned}
$$

Other authors follow GISP2 for the period 25-16 ka cal BP (de Abreu et al. 2003).

$N=$ number of calibrated radiocarbon determinations in the frequency curve.

than western Europe. If correct, this suggests the spatially extensive use of the French reindeer steppes by hunting parties with predominantly dispersed set- 


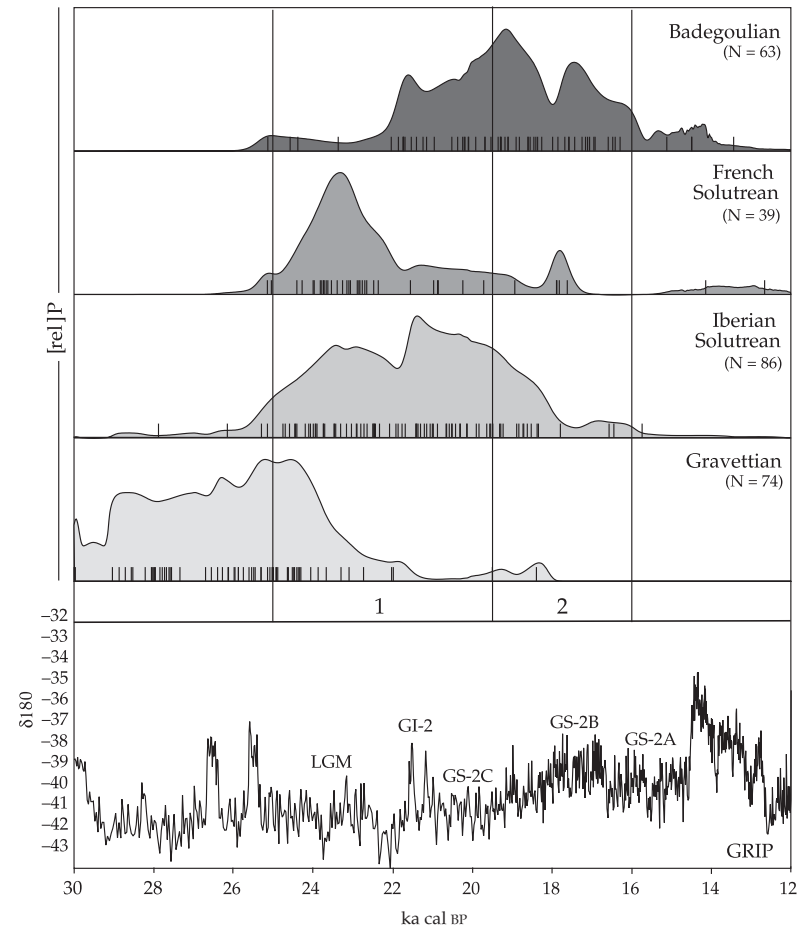

Figure 3. Population events $1 \mathcal{E} 2$ (LGM to GS-2b) in Iberia and France. In CALPAL (Weninger E Jöris 2000) individual radiocarbon determinations are defined by their median value and standard deviation. The Gaussian curves, normalized for equal area, present the summed radiocarbon dating probability (rel)P. Each determination has equal weight independent of dating precision. Calibrated curves are shown by ATU2s. In Iberia, the Solutrean is well represented from the LGM through GS-2c. In France the relative presence of the Solutrean, as indicated by the distribution of the radiocarbon determinations, is substantially less suggesting a small demic diffusion north followed by population contraction back to the Cantabrian refugium. The wider context for the development of the Badegoulian (= Early Magdalenian) ATU2 is therefore the contraction of population back into Iberia after GI-2.

tlement patterns, whose population focus lay to the east, rather than the south.

Settlement type in both Cantabria and southwest France during Population event 1 is dominated by rockshelters as opposed to open sites. Within Population event 1 we include the relatively short-lived population expansions from Cantabria (ATU2 Solutrean) and central Europe (ATU2 Badegoulian) into southern France (Fig. 3). Moreover, the ATU2 Badegoulian appears as an abrupt replacement of the ATU2 Solutrean that suggests a population incursion. We expect that

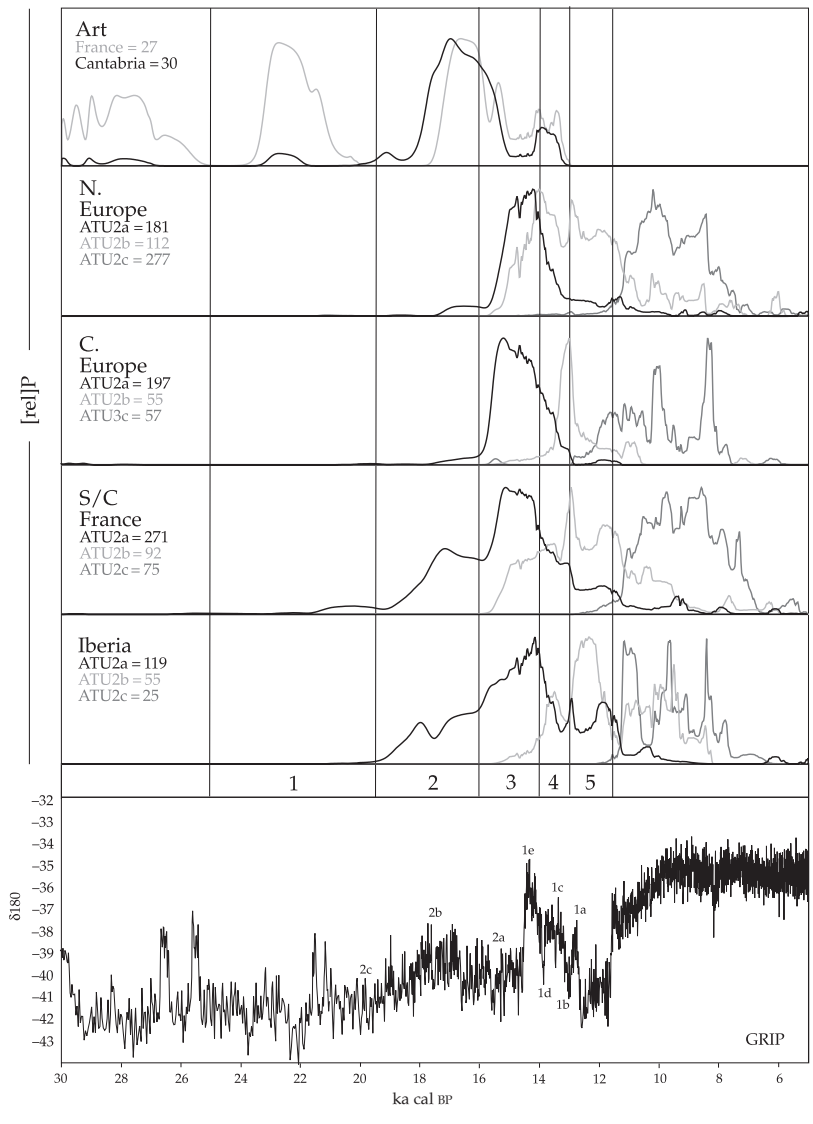

Figure 4. Population events 3-5 (GS2b to GS1) radiocarbon dating probabilities by ATU2. Later Magdalenian $=$ ATU2a; Epipalaeolithic $=$ ATU2b; Mesolithic $=$ ATU2c. It is expected that an audit of the dates by precision, accuracy and their archaeological integrity will reduce the outliers in earlier population events (Pettitt et al. 2003).

similar demographic pulses were a regular feature of long-term human refugia.

Population event 2: initial demic expansion 19.5-16 ka вР The radiocarbon determinations in Figure 4 form the proxy data to infer significant demographic change during GS- $2 b$ and the first half of GS-2a. In all areas this is associated with Magdalenian ATU2s (Fig. 4). The change takes the form of an initial step and plateau (Fig. 2) in all regions outside the Cantabrian G refugium before the major rise in the frequency of calibrated determinations during the second half of GS-2a. This occurs during Heinrich event 1 (17.6-14.9 ka вр), at which time very low summer sea surface temperatures (SST) have been recorded in core MD952040, $125 \mathrm{~km}$ off the Portuguese coast (de Abreu et al. 2003). 
In both France and Iberia Population event 2 corresponds (Fig. 4) to a pronounced peak in directly dated cave art. The number of such sites is currently small $(\mathrm{N}=14)$ but it is noteworthy that an earlier peak in France corresponds to the Solutrean population expansion we have identified (Fig. 3) and which also corresponds to low summer sea surface temperature in the Iberian Atlantic during Heinrich event 2 (24.3-23.1 ka вр) (de Abreu et al. 2003). Cave art may therefore have been associated in some regions with small-scale demic expansion out of the Iberian $G$ refugium that increased population density at the margins of occupation. This contrasts with earlier interpretations (Jochim 1983) that linked the appearance of cave art to increased population density as people moved into refugia during the LGM and used art as a means to establish territorial rights to key resources such as salmon runs.

In this light, the comparison of directly-dated cave art with the GISP2 curve of d'Errico et al. (2001) is intriguing. Using a sample of 146 dates from 27 sites pertaining either to human activity in decorated caves or directly to parietal art, the authors note a peak of activity in Heinrich event 1 , into which 16 decorated cave sites fall at one sigma. Although the authors recognize that the data are provisional, and bearing in mind that the data base may not be as reliable or representative as they suggest (Pettitt \& Bahn 2003; Pettitt \& Pike 2001), taken at face value the results suggest increased artistic activity in France and Spain during the climatic deterioration of Heinrich event 1. This pattern stands in clear contrast with the earlier severe conditions during Heinrich event 2 into which very few (2-4, attributable to the Solutrean ATU2) decorated sites fall at one sigma. The authors initially interpret this contrasting pattern as suggestive of a lack of climatic determinism on artistic activity. They speculate, however, that the different nature of Heinrich event 2 and Heinrich event 1, particularly in terms of aridity and humidity, may have made caves inaccessible during the former, and generally favour an interpretation in which climate affects artistic productivity in caves as they are rendered inaccessible due to snow and ice. By this argument, the lack of humidity (and therefore ice production in and around caves) was not an obstacle to access in Heinrich event 1 , thus the artistic floruit.

This climatically-determined variation remains a possibility, although we favour an alternative, first proposed by Housley et al. (1997). We suggest that this small demographic step, inferred from the increased number of radiocarbon determinations, represents a stage of pioneer settlement in the process of demic expansion as regions beyond the $\mathrm{G}$ refugium were explored, assessed and utilized in a more systematic fashion and on a more regular basis. We see the possible increase in artistic activity as an integral part of this new social process, a new way of occupying and giving meaning to the land. This settlement pattern occurred over much of western Europe where the main population focus now included southwest France as well as regions in Iberia outside Cantabria and Portugal. Settlement type now comprises both open and naturally-sheltered sites. Rather than the geography of cave art being accounted for by locally rich environments and in-migration to the refugium, as Jochim $(1983 ; 1987)$ argued, it is instead associated with the process of geographical expansion.

\section{Population event 3: main demic expansion 16-14 ka вP} The principal Late Glacial demic expansion occurred in two phases in western Europe (Fig. 5) over a 2000year period in GS-2a and GI-1e. In phase 3.1 (Tables $3 \& 4$ ) there is a significant increase in the number of calibrated determinations in all regions between 16 ka and $14.7 \mathrm{ka}$ cal вр. During this 1300-year period the dominant ATU2 is the Late Magdalenian. Furthermore, the sequence in the radiocarbon curves (Fig. 5) confirms earlier archaeological studies (Housley et al. 1997) and the interpretation of molecular evidence (Torroni et al. 1998) that within western Europe, demic expansion was from the south to the north and associated with a rapid increase in the metapopulation (Bocquet-Appel \& Demars 2000b; Demars 1996; Straus 2000a).

Phase 3.2 of the main demic expansion is represented in two of the three regional radiocarbon curves (Fig. 4) as a plateau that lasts throughout GI-1e (=Bølling interstadial). These 700 years partly coincide with a small plateau in the calibration curve (Weninger \& Jöris 2000). This is not considered significant because at this time in southern Iberia the frequency of determinations continues to rise (Fig 5).

Following Housley et al. (1997) we describe the archaeological settlement pattern in Population event 3 as residential. Large size, open-air campsites are known (Straus et al. 1996) from Lake Neuchâtel and the Neuwied and Paris basins, and these are matched by substantial rock shelter occupations in the Rhine-Danube watershed, the uplands of southern Germany, Thuringia and Belgium. Smaller-scale rock shelter occupations are known from the periphery in the British Isles (Barton 1999; Barton et al. 2003) and are comparable in site size to the pioneer settlement of earlier Population event 2. No doubt small open settlements extended into other northern areas, such 


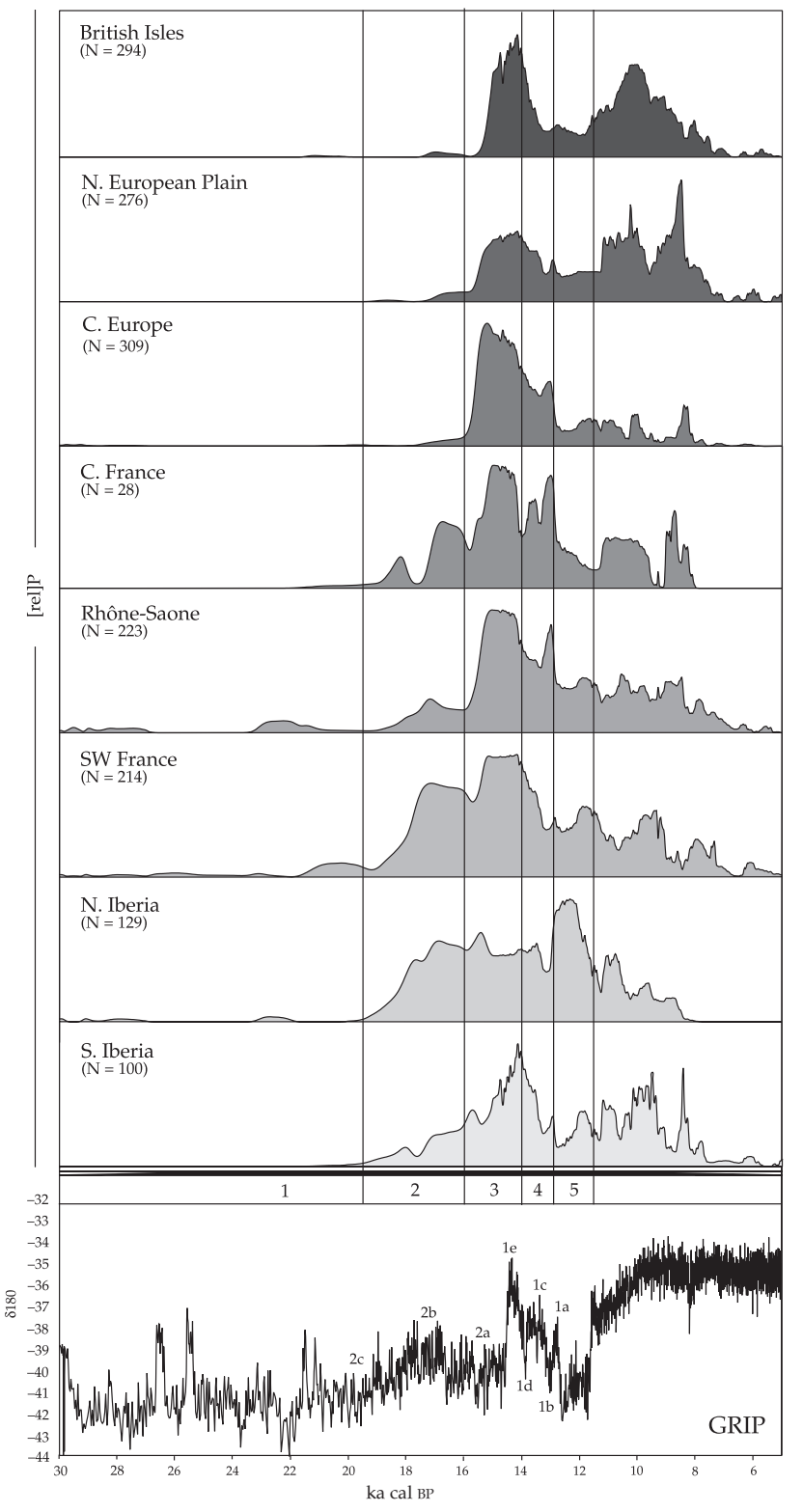

Figure 5. Population events 3-5 (GS-2b to GS-1): radiocarbon dating probabilities by region. ATUs represented are Later Magdalenian, Epipalaeolithic and Mesolithic. As in Figure 4 the dates are unaudited.

as Doggerland (Coles 1998), now inundated by the North Sea.

Archaeological evidence suggests two dispersal corridors for Population event 3 to the west and east of the Massif Central (Thévenin 1995). The eastern corridor following the Rhône-Saône-Rhine rivers is supported by evidence for the long-distance transfer of raw materials including Mediterranean shells and Baltic amber (Floss 2000) and is studded with residential settlement sites (Street et al. 2001).

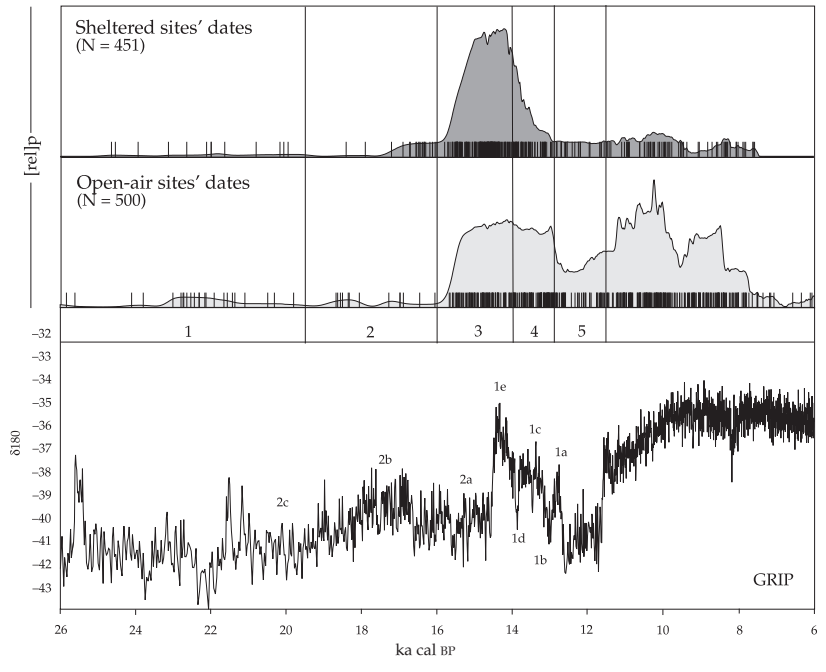

Figure 6. Open and sheltered sites' dates from northern France and North Central Europe (regions 6-9 Fig. 1) in population events $3-5$.

Population event 4: population stasis, 14-12.9 ka вР The interpretation of this population event as stasis rather than contraction illustrates the importance of combining radiocarbon determinations, when used as proxy data for past demography, with archaeological information on settlement patterns. The face-value interpretation from the calibrated curves (Fig. 5) is that after $14 \mathrm{ka}$ cal вр population declined in most regions of western Europe.

Figure 6, however, shows that when the radiocarbon determinations from northern Europe (Fig. 1) are compared for two classes of sites, open sites and rock shelters / caves, then the reason for the decline in the proxy population curve becomes apparent. Naturallysheltered locations were dominant in both population events 2 and 3 . This settlement type, however, did not play a significant part of the continuing occupation of the region. On the contrary, open-air campsites continued in importance throughout GI-1 and remained largely unaffected by climate change until the last sub stage GI-1a. We interpret these frequency data as changes in regional settlement patterns, for example from dispersed to nucleated, rather than a decline in the size of the metapopulation.

Population event 5: population contraction, 12.9-11.5 ka вР The impact of GS-1 (= Younger Dryas) on population size in northern Europe was considerable (Fig. 6) and is confirmed by archaeological surveys (Straus et al. 1996). This northern area, however, was neither abandoned nor used as infrequently as in Population 
events 1 and 2 (Fig. 2). This suggests a higher metapopulation for western Europe than the refugium minimum (Bocquet-Appel \& Demars 2000b) and from this deme came the Holocene/Mesolithic recovery and population growth.

\section{Population history and Late Glacial climate change}

The S2AGES proxy data for demic expansion can be considered in the light of two current interpretations of the Greenland ice-core record and its significance for the North Atlantic (Lowe et al. 2001; Walker et al. 1999). At issue is the role of climate forcing in the expansion of human populations. Ameliorating climate at the end of the European ice ages is believed to drive the process of northward expansion of many species from southern refuges (Hewitt 1996; 1999; Willis \& Whittaker 2000). For this model to stand for human expansion it is necessary to interpret the radiocarbon and GRIP data as time-transgressive. This expects the environmental response in the lower latitudes of Europe to precede by some time the signal for climate change recorded in the high-latitude Greenland cores. This is indeed the case with Population event 3.1, the main demic expansion (Tables 3 \& 4) starting in the cold GS-2a rather than the warmer GI-1e. Moreover, multi-proxy environmental evidence from terrestrial locations in northern Europe (Walker et al. 2003) suggest this may be the case there also. These data indicate that warming was underway by $15.5 \mathrm{ka} \mathrm{cal} \mathrm{BP}$, some 800 years before the onset of GI-1e, and that a timetransgressive interpretation between palaeoclimate archives at different latitudes is appropriate.

To investigate this further we conducted a correlation of the climate and radiocarbon time series. A visual inspection of Figure 7 indicates a temporal correlation between changes in radiocarbon density and climate variations for France and northern Europe and, to a lesser degree, Iberia. It is possible to quantify measures of correlation by comparing the GRIP climate curve and the radiocarbon data from S2AGES at each instant in time using Pearson's linear product moment or by Fourier techniques (Chatfield 1980; Press et al. 1993). The latter approach naturally allows the correlation to be calculated at arbitrary time shifts $\tau$ between the two time-series.

The result is that the magnitude of the peak determines a measure of the correlation; +1 for perfect correlation, 0 for no correlation and -1 for negative correlation. The shift of the peak determines at what temporal difference the two time-series are best correlated. Table 7 illustrates how this would apply to
Table 7. Explanation of Corr $(\tau)$ peak position in time.

\begin{tabular}{|l|l|l|}
\cline { 2 - 3 } \multicolumn{1}{c|}{} & $\operatorname{Corr}(\tau)$ is +ve & $\operatorname{Corr}(\tau)$ is -ve \\
\hline Positive $\tau$ & $\begin{array}{l}\text { Climatic warming } \\
\text { precedes increase in } \\
\text { radiocarbon date density }\end{array}$ & $\begin{array}{l}\text { Climatic warming } \\
\text { precedes decrease in } \\
\text { radiocarbon date density }\end{array}$ \\
\hline Negative $\tau$ & $\begin{array}{l}\text { Radiocarbon date density } \\
\text { decrease precedes climatic } \\
\text { warming }\end{array}$ & $\begin{array}{l}\text { Radiocarbon date density } \\
\text { increase precedes climatic } \\
\text { warming }\end{array}$ \\
\hline
\end{tabular}

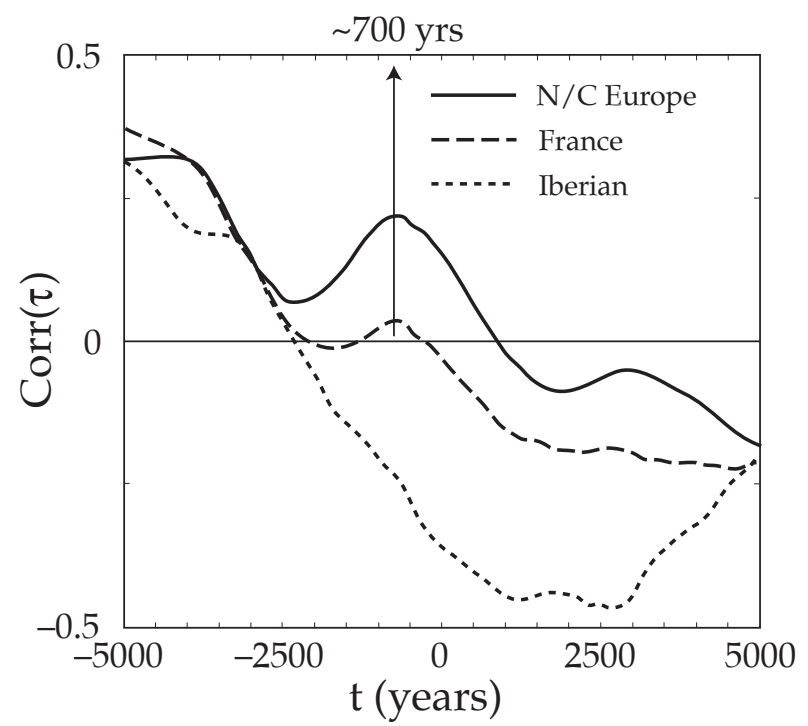

Figure 7. Correlation analysis of the radiocarbon curves in Figure 2 (see also Table 7). Caution needs to be exercised regarding the statistical significance of the correlation coefficients. While their magnitude suggests statistical significance, they are based on correlating relatively short and aperiodic time series, and should be taken as indicators as opposed to absolute markers (Chatfield 1980).

the order of events for our data and can be used to explain Figure 7.

Of greatest interest is the positive peak that occurs at around $\sim 700$ in both the northern European and French data. This indicates a positive response in radiocarbon density 700 years before climatic warming. These peaks occur in the same place for both France and northern Europe, providing us with confidence that this represents some population event. By contrast, the Iberian data show a negative correlation around this time period, suggesting that site densities decreased as the climate warmed. We can speculate that the correlation plot implies an expansion from one region to the other as a result of changes in temperature. While the correlation supports the southern refugia hypothesis in principle, however, 
the trough in Figure 7 is very broad in comparison to the peaks, making its relation to human migration inconclusive.

An alternative model that expansion is not directly linked to ameliorating climate and that the two records are time-locked is supported by marine evidence. High-resolution records from an Iberian ocean core (de Abreu et al. 2003) show in-phase oscillations with GRIP and GISP2 during the last glacial cycle. Significantly the Heinrich event 1 dated 17.6-14.9 ka BP represents the coldest sea surface temperatures off Iberia in the last $70 \mathrm{ka}$ and coincides with the major human expansion during population events 2 and 3 (Tables 3 \& 4). Environmental forcing on population expansion was therefore linked instead to colder climatic conditions in western Europe, and the earlier Solutrean ATU2 pulse (Fig. 3) during Heinrich event 2 confirms this.

One solution to the conflicting evidence over the role of climate in human expansion might rest in the model of southern refuges. Climate modelling using sea-surface temperatures (van Andel et al. 2003) and evidence from the palaeobotanical (Willis et al. 2000) and faunal (Stewart 2003) archives points to the existence of unexpected, or cryptic refuges, during cold phases north of Europe's continental divide. These refuges may have been small in extent and limited in duration but would have acted as an attractor to human populations with an extensive settlement network.

By comparison with the human expansion in Heinrich event 1 , the contraction we document in Population event 5 appears in phase with the GRIP stratotype but is not related to any Heinrich event. This association supports Foley's (1994) larger analysis of environmental change and evolutionary events among hominins, in which the primary influence of climate is on extinction rather than speciation. We conclude that the expansion and contraction of mobile Late Glacial populations in western Europe may have been responding to fine-scale climate change in similar ways. At these smaller temporal and spatial scales, population dispersal and decline are analogous to speciation and extinction (Gamble et al. 2004).

\section{Comparison with genetic data}

Our case study allows us to make at least two comparisons between the archaeological and molecular data. These relate to:

1. age estimates from radiocarbon and molecular clock models for founder effects and population expansions;
2. ATU2 distributions and phylogeographic patterns.

The molecular clock

Phylogeographic analysis of modern Europeans indicates a major founder effect in the Late Glacial, with an age estimated by using the mitochondrial DNA molecular clock at c. 11-16,000 years ago (Achilli et al. 2004; Loogväli et al. 2004; Pereira et al. 2005; Richards et al. 2000; Torroni et al. 1998; 2001). The radiocarbon chronology presented here provides the first independent assessment of this estimate with calibrated determinations (Table 3; Fig. 2). The agreement is good for the start of Population event 3 when population was rapidly expanding into northern Europe. It is not yet possible, however, to be precise about the duration of the constriction itself, except to suggest from the proxy radiocarbon data for regional demography that the neck of the bottle was particularly elongated.

But before we congratulate ourselves on the convergence of two disciplines on the same date by different methods we should remember the errors involved in the estimation of ages using the molecular clock. These include uncertainty in the rate of the clock itself, which is very hard to quantify, large sampling errors, and the impact of demographic processes such as founder effects. For example, mtDNA haplogroup $\mathrm{V}$ has been identified as an important marker for European recolonization from a western refuge (Torroni et al. 1998). When all populations were included the time depth for its appearance was estimated at $11,200 \pm 2700$ years. Certain populations, however, had unusually high frequencies of the haplogroup, probably owing to local founder effects. When these outliers (Sami, Croatians and Basques) were excluded, the estimate increased to $14,600 \pm 3600$. Finally, when the sample was analyzed on a west-east axis across Europe (with outliers still excluded) the age of haplogroup V was 16,300 years in the west (assumed to be the best estimate for the age as a whole) and 8500, in the east (Torroni et al. 2001), again with large standard errors. Furthermore, it is worth noting that while these refinements may from the archaeologist's perspective appear to be shifting the point estimates considerably, the 95 per cent confidence intervals for all of these estimates (which themselves account only for sampling error and do not take into account uncertainty in the mutation rate) overlap substantially.

Such molecular clock estimates are therefore notoriously ball-park and always come with caveats. This implies that the relationship between the genetic phylogeographies and the archaeological data needs to be reversed. Rather than verifying such 
estimates by independent radiometric means, the chronology should in the first instance be based on audited archaeological sources (Pettitt et al. 2003). By examining an archaeologically well-documented population event, as we have done here for western Europe, correlation may well be possible between archaeogenetic and archaeological data. A more appropriate relationship between the disciplines, however, is for archaeogenetics to make use of the more reliable chronologies produced by archaeology in order to test the scale of demographic changes within an independently-obtained radiometrically-based timescale. Genetic data can indicate that there were indeed major demographic changes at around this time in the Late Glacial that have left signatures in the modern European gene pool; they could not, at least for the foreseeable future, resolve the issue of whether these changes began at 15,000 years ago rather than, for example, 16,000 years ago.

\section{ATU2s and phylogeographic patterns}

It is tempting to match ATU2s with phylogeographic patterns in the same way that classical genetic marker frequencies have been matched with archaeological patterns in the past (Cavalli-Sforza et al. 1988). For example, the eastern origins of the Badegoulian ATU2 may be reflected in the distribution of mtDNA haplogroups $\mathrm{H}$ and pre- $\mathrm{V}$. These are inferred to have had an origin around 20-30 ka BP either in eastern Europe or the Near East, and to have re-expanded from southwest Europe 12-16,000 years ago (Richards et al. 2000; Torroni et al. 1998; 2001). The Y-chromosome haplogroups R1b and I1 a show a similar pattern (Rootsi et al. 2004; Semino et al. 2000). These patterns chime well with archaeological assessments of the geographical spread of this ATU2 (Street \& Terberger 1999; Terberger \& Street 2002).

But what is implied in such matching? At most, simply a contingent link between certain individuals moving across the landscape around 20,000 years ago, who took with them both particular mtDNAs and / or $Y$ chromosomes and were part of a certain way of life. This should not be taken to imply that, in traditional archaeological terms (Box 1), a culture such as the Badegoulian would be expected to have a distinctive genetic signature. That would only be the case if the notion that such an archaeological culture represents a 'people', first expressed by Childe (1925), still holds. But to include a genetic component in such an ethnic mix of attributes requires a primordial view of race and culture where our identity is literally in the blood (Jones 1997), as well as archaeologically shaped in stone (Bordes 1968).
While such primordial views have been discounted on archaeological and ethnographic grounds (Zvelebil 2001; 2002), they nonetheless underpin aspects of the cognitive origins synthesis when it comes to language. For example, human geneticists have traditionally regarded the Basque population of southwest France and northeast Spain as a 'Palaeolithic relict', by conflating their position as both a genetic outlier and a linguistic isolate (Cavalli-Sforza et al. 1994). It may therefore seem natural to associate the refugium population biologically with the ancestors of the Basques. Recent analyses, however, have suggested that the majority of both mtDNA and Y-chromosome lineages in most European populations, and not only the Basques, date to the late Palaeolithic/Mesolithic (McEvoy et al. 2004; Richards et al. 2000; Semino et al. 2000). The status of the Basques as a genetic outlier is probably more a result of isolation and the random genetic drift that occurs in small populations than any particular claim to 'relict' status.

Population size is of particular interest in this context. Returning to the Badegoulian, as an archaeological culture rather than an ATU2, what would be the population implications if a link to mtDNA haplogroups $\mathrm{H}$ and pre-V were established? Most archaeologists would regard such a culture as a significant population unit, by which is implied a minimum size of 500 people to ensure reproduction and hence its long-term persistence as an archaeological entity (e.g. Constandse-Westermann \& Newell 1991; David 1973). Moreover, a degree of group closure is expected and traditionally this should be reflected in style territories (Clark 1975; Gilman 1984; Wobst 1974). We are struck, however, by the similarities with an earlier ATU2, the Aurignacian, that was also a generalized technology well suited to the needs of a dispersing population (Davies 2001).

Estimates by Bocquet-Appel \& Demars (2000b) of the metapopulation in the Late Glacial of western Europe, excluding Iberia, range from 9000 in the refugium to 40,000 in the expansion phase. Since the Badegoulian comes before the demic expansion in Population event 3 (Fig. 3) we might expect something of the order of 18 connubia or maximum bands of 500 persons. This, however, is to conflate the $\mathrm{M}$ and $G$ refugia which, as we have shown above, need to be distinguished for a mobile adaptive strategy that thrived on the principles of social and geographical extension. These principles were articulated along ego-based networks (Gamble 1999) and enshrined in the dynamic of fission-fusion. One of us (Gamble 1983) has been arguing for some time for a spatiallyextensive model of Upper Palaeolithic populations 
to reflect such individual mobility in the Pleistocene environments of Europe. An awareness of the potentially small numbers involved underpins colonization models in both the Early (Davies 2001) and Late (Housley et al. 1997) Upper Palaeolithic. While the radiocarbon curves presented here cannot provide estimates of population numbers, when compared between regions and through time, they strongly suggest either very low numbers or intermittent occupation in much of Europe north of the continental divide prior to Population event 3.

More accurate estimates of the metapopulation will, however, have little impact on clarifying the founder effect and bottleneck which can be inferred from the molecular data. The best estimate for the numbers involved in the founder effect prior to Population event 3 is of a few families situated at the leading edge of the metapopulation to which they belonged.

Instead the interest in estimating metapopulation sizes relates more to Shennan's $(2001 ; 2002,55)$ observations on the scalar importance of numbers in the process of cultural transmission. For example, the estimated rise in the metapopulation in Population event 3.1 from some 9000 to 40,000 in western Europe, excluding Iberia, could have occurred over 1300 years (Table 4 ). Bocquet-Appel \& Demars (2000b) further estimate, using archaeological site data, that population density within the $G$ refugium increased from 9.4 to 17.3 persons per $100 \mathrm{~km}^{2}$, while in areas of France outside the refuge the rise was from 0.7 to 3.1 persons per $100 \mathrm{~km}^{2}$. A larger metapopulation and regionally increased densities would, according to Shennan's model, have radically altered the selection environment for cultural transmission. In particular, a larger population affects the likelihood of cultural drift occurring and the resultant loss of 'useful arts' (Bocquet-Appel \& Demars 2000b) which has always bothered anthropologists and archaeologists (Jones 1977). It is noticeable therefore that the ATUs of Population events 3 to 5 are more widely and accurately recognized by archaeologists than those associated with the two earlier events (Tables 3 \& 4). This classificatory confidence is clearly shown in Figure 4 on which three ATUs are plotted - Later Magdalenian, Epipalaeolithic and Mesolithic. Where the graphs overlap significantly, as in northern Europe with the Magdalenian and Epipalaeolithic ATUs in Population event 3 , there is obviously disagreement among archaeologists about how to classify and what criteria to use. Only later in Population event 4, and then again in the Mesolithic, is there clearer agreement in assigning material to agreed ATUs. This is shown by the curves now replacing each other in classic battleship fashion (Gamble 2001; Figs. 3 \& 5). This same pattern is seen in the battleship curves for central Europe and France (Fig. 4). We interpret this more robust patterning as an outcome of larger population numbers in these Population events and their impact on the structure and transmission of cultural life in the Late Glacial. The robustness of archaeological taxonomies therefore depends upon the population numbers that archaeologists are sampling rather than on the fortuitous appearance of distinctive type fossils. A further example of taxonomic difficulties resulting from low population numbers would be the Creswellian ATU2 of Britain where a long-running debate on its classification, taxonomic status and significance is still far from resolved (Barton et al. 2003; Campbell 1977; Garrod 1926).

\section{The archaeology of colonization and historical linguistics}

In the 'grand synthesis' advocated by proponents of the cognitive origins approach (Bellwood \& Renfrew 2002), demographic expansions fuelled by the first appearance of agricultural surpluses were the motor for the spread of the major widely-distributed language families, such as Niger-Kordofanian, Austronesian and Indo-European. If this were the case, results from archaeology, genetics and historical linguistics would be expected to map closely onto one another. In limited instances this seems to be the case - for example in the expansion of Oceanic speakers across the Pacific, and of Bantu speakers into southern Africa - but there has been much discussion as to whether these situations can be generalized, particularly in relation to the Indo-European language family. Renfrew (1987), for example, suggested that Indo-European protolanguages were first spoken in Anatolia and were dispersed through Europe by an early agriculturalist 'wave of advance' such as that proposed by Ammerman \& Cavalli-Sforza (1984) to explain the east-west distribution of some European genetic markers. On this view, the Basques, as mentioned earlier, represent a Mesolithic 'relict' population who resisted the advance of the farmers and thereby held on to their pre-Neolithic language.

There has been a recent and widely-publicized attempt to support this agriculturalist-dispersal model (Gray \& Atkinson 2003) by - rather ironically, given Renfrew's (1987) stance on the issue - reintroducing glottochronology by the back door of a maximumlikelihood approach to the phylogenetic analysis of genetic sequence data (which can much more reasonably 
be assumed to have evolved at a roughly constant rate). It has been greeted with some enthusiasm amongst bioinformaticians (Searls 2003) but, not surprisingly, with more than a little scepticism by linguists working in the area (Balter 2003). The growing evidence that the major signal in European genetic lineages predates the Neolithic, however, creates serious problems for the agriculturalist perspective. If western Europe was, to a large extent, repopulated from northeast Iberia then, since place-name evidence suggests that people in this source region spoke languages related to Basque before the advent of Indo-European, the obvious corollary would seem to be that the expanding human groups should have been Basque speakers. There is, however, no evidence for this in place-names or linguistic substrata in northwest Europe, even if it could be argued that the spoken language itself was later subsumed by Indo-European incursions - which itself becomes increasingly difficult, as the genetic evidence for continuity of genetic lineages in western Europe accumulates.

It might almost seem that the most fruitful avenue for advocates of the cognitive origins synthesis to pursue might be the arrival of a proto-Indo-European dialect in southwest Europe with the Badegoulian ATU2, in the refugium phase, and its subsequent codispersal with the Magdalenian ATU2 into western and northern Europe. It seems unlikely, however, that historical linguists who were not prepared to journey with Renfrew back to the early Neolithic would welcome the concept of a Late Glacial dispersal of Indo-European languages in western Europe. We might do better to recall that there is simply no clear way to knit together a particular language and a particular group of people in the pre-literate past, or a particular material culture in the archaeological record - particularly if we accept Renfrew's (1987) strictures on the value of linguistic palaeontology to archaeology. In this article we have emphasized this point by replacing terms such as culture that are used in the reconstruction of population history with the 'baggage free' ATU.

In fact, the recent history of attempts to make such connections does little to inspire confidence in the project. The congruences between genetic and linguistic barriers within Indo-European in Europe (Barbujani \& Sokal 1990) have been found wanting (Sims-Williams 1998). Novel conclusions about the spread of language families, such as those of northeast Europe, have not gained wide support (Bandelt et al. 2002; Sims-Williams 1998), and even in regions where two major language families meet, there is remarkably little association with genetic patterns (Zerjal et al.
1991). The combination of genetics and historical linguistics has also become notorious for applications of the family-tree model far beyond what most linguists would consider legitimate (e.g. Cavalli-Sforza et al. 1988; Dixon 1997; Sims-Williams 1998).

If even the proto-lexicon is washed away, as Renfrew (1987) has advocated, it is difficult to see what useful lessons historical linguistics might still have for the archaeology of colonization. The distributions of genetic markers in modern populations can, to some extent, be used to identify and even (using an identification of founder lineages and a suitable calibration of the molecular clock) estimate the timing of movements in prehistoric times. These can be tested against hypotheses of migration versus acculturation based on the archaeological record for the arrival of new material culture complexes. Such dispersals may or may not have been the vehicles for the spread of particular language families, but it is difficult to see how it might be possible successfully to combine genetic or archaeological evidence with that of linguistics without risking the circularity often witnessed in the more naive work of human population geneticists.

\section{Conclusions: agricultural thinking and population history}

If we knew the history of humankind ... we could see that genetic and archaeological data are part of the same story. Since we know little of our past, and the sciences that study it often provide separate (and noncommunicating) fragments of knowledge, it is important for them to learn how to help each other (Cavalli-Sforza \& Cavalli-Sforza 1995, 129).

We have learned in the past decade that population history can indeed be investigated through an interdisciplinary synthesis of archaeological and genetic data. The pioneering work of Cavalli-Sforza and the more recent developments in cognitive archaeology and archaeogenetics have fused the archaeological approaches of culture history and culture process into an exciting and challenging new field of enquiry. In particular, those behind the cognitive origins synthesis have been instrumental in pushing these changes forward (e.g. Renfrew 2000).

Our aim in this article has been to step down a scale from such grand designs and examine population history through a detailed study of radiocarbon dates at a sub-continental rather than global scale. In answer to our four questions (p. 56) we have shown that:

1. radiocarbon estimates used as dates-as-data are an appropriate proxy for the study of population history at a sub-continental and regional scale; 
2. climate change provides no simple explanation for the major demic expansion that we have identified after 16,000 years ago;

3. the links between genetic and archaeological data are extremely supportive for the study of regional population history as shown, for example, by the timing of demic expansion, as well as confirming its direction from southern refugia;

4. the role of historical linguistics in the cognitive origins synthesis is at best unconvincing. It is unclear to what these chronologically untethered data refer at our scale of analysis. We find them a distraction to the development of population approaches since historical linguistics returns us to the unproductive search for origins and identities.

What we have examined in this article are the implications of bringing quaternary science and a calibrated radiocarbon record to the study of 15,000 years of population history. Climate change is an essential component of the process and the opportunity now exists to understand human tolerances and preferences to variable scales and rates of change (Davies \& Gollop 2003; Davies et al. 2003; Gamble et al. 2004). The archaeological data, presented here as part of the S2AGES radiocarbon data base, provide the overall pattern of western European population history in terms of at least five significant population events and a geographical assessment of the direction of expansion. With a population history approach we need a new vocabulary to describe the data and here we have followed Foley's lead with ATUs (Box 1). In this article we use ATUs to simplify the plethora of archaeological terms and the discrepancies in their application. It may be, however, that the five population events (Tables $3 \& 4$ ) are the chronological ATUs we now need to employ. They can be compared in terms of their genetic signatures as well as the evidence from sites for faunas, lithics and all the other aspects of the material record of past societies.

To capitalize fully on this new approach, however, we must shrive ourselves of some 'agricultural thinking' when it comes to population history and the archaeology of mobile, small-world societies. By 'agricultural thinking' we refer to models and explanations that on examination turn hunters and gatherers into farmers. Agricultural thinking is deeply embedded in the cognitive origins synthesis as well as many Palaeolithic case studies that reconstruct, as if pursuing an ethnographic enquiry, long-term changes in the seasonal use of landscapes and regions (Bailey 1997; Eriksen 1991; Henry 1995; Higgs 1975).

One widespread example of such agricultural thinking is site-catchment analysis (Vita-Finzi \&
Higgs 1970) that draws concentric cost rings around Palaeolithic sites and then analyzes the resources they contain as the reason for locational decisions by Palaeolithic people. But as Leroi-Gourhan $(1993,326)$ pointed out, this bird's eye view belongs to farmers and their granaries. The world of a hunter is instead linked to an itinerary: a track, not a catchment.

Another example of agricultural thinking is the idea that population history is positively fuelled by warming climates. Crops do badly in the cold and wet and so by analogy did Palaeolithic hunters and gatherers, those bad-weather cave-dwellers of European prehistory. Our case study has shown, however, that such simple views of climate do not necessarily drive population history and in particular demic expansion. Warming was not the automatic pull for populations to move north.

But perhaps the strongest examples of the hold of agricultural thinking on European prehistory come from the cognitive origins synthesis. First, Renfrew's $(2001,127)$ sapient paradox states that only with agriculture and settled life did 'decisive happenings' occur. In other words we had to wait 30,000 years for the stimulation of the built environment of villages to become symbolically fully sapient. Second, CavalliSforza et al. (1994) has argued that the genetic history of Europe is to be understood as the spread of agriculturalists. Instead we have shown that western Europe preserves two steep and relatively slow (Housley et al. 1997; Table 5) travelling waves of demic expansion, that began about 16,000 (hunters) and 9000 (farmers) years ago (Table 1: $C \& E$ ). From the perspective of population history, the mtDNA and Y-chromosome data accord more significance to the older travelling wave.

Both examples of agricultural thinking have a single, and acknowledged, origin - Gordon Childe. He firmly believed that history started with farming and that migration explained changes in archaeologi$\mathrm{cal}$ materials. His grand narrative has dominated European prehistory ever since (Sherratt 1997) and, as we have just seen above, continues to exert its distortions as new syntheses are shaped. We therefore finish with a question raised by our own interdisciplinary approach. Is it time to abandon the agricultural thinking of Childe in European prehistory and instead discover through population history a new narrative for our data, methods and scientific partners? Our answer is, Yes. Let us turn those ploughs into people and look for founders not origins.

\section{Acknowledgements}

The compilation of S2AGES is supported by a grant from the 
Leverhulme Trust (F/00180/I). Additional funding from the British Academy for a Research Readership and Research Grant was awarded to Gamble. Bernard Weninger, Olaf Jöris, Nick Barton, Robert Foley, Mike Walker, Jean-Pierre Bocquet-Appel, Martin Street, Tjeerd van Andel, Hans-Jürgen Bandelt, Kathy Willis and Cheryl Ross provided valuable comments. Penny Copeland prepared the figures.

Clive Gamble

Centre for Quaternary Research Department of Geography Royal Holloway University of London

Egham

TW20 0EX

Email:clive.gamble@rhul.ac.uk

William Davies Centre for Quaternary Research Department of Geography Royal Holloway University of London

Egham

TW20 0EX

Paul Pettitt

Department of Archaeology University of Sheffield

Northgate House

West Street

Sheffield

S1 4ET

Lee Hazelwood AHRB Centre for the Evolutionary Analysis of Cultural

Behaviour

University of Southampton Avenue Campus

Highfield

Southampton

SO17 1BF

Martin Richards

Faculty of Biological Sciences

L.C. Miall Building

University of Leeds

Leeds

LS2 9JT

\section{Comments}

From Lawrence G. Straus, Department of Anthropology, University of New Mexico, Albuquerque, NM 87131, USA; 1straus@unm.edu.

With characteristic vision, flair and - yes - audacity, Clive Gamble and colleagues draw on a wide variety of archaeological (especially radiocarbon) and genetic evidence to paint with very broad strokes a picture of the Tardiglacial re-colonization of northern Europe after the refugium experience of the LGM. I am, needless to say, in general agreement with their archaeological conclusion, but leave the genetic and linguistic conclusions to the specialists to debate from more informed positions than mine.

It is clear that the entire one-million-year history of settlement in Europe has been characterized fundamentally by repeated expansions and contractions of the human range in relationship to the climatic cycles of interglacials/interstadials and stadials. I daresay that this is a fact of life which has not come to an end, but rather will wreak havoc on an unprecedented scale upon the dense, agriculturally-dependent populations, not only of Europe itself, but also of the World, merely in the opening centuries of the inevitable temperature downturn that will culminate in 'Isotope Stage 0'. It is equally obvious that it is with the Late Last Glacial (i.e. Stage 2) that we have unprecedented archaeological, palaeoclimatic, and radiometric control which can permit such exercises at tracing the movements and relative densities of human populations across the landscapes of Europe, while, for earlier periods (even the much-studied Stage 3 - mostly beyond the range of credible radiocarbon dating) our levels of resolution are still weak or indeed miserable. The picture that Gamble et al. paint of retreat, refugium and recolonization is fully in line with the research and thinking of many Continental, British and American scholars of the Upper Palaeolithic in recent years. The roles of regional demography and shifts therein are factors that I have been stressing in my own work for some 30 years (e.g. Straus 1977; 1991; 1992; 2000a; Straus et al. 1997; 2000a,b). It is apparent that the Upper Palaeolithic foragers - highly dependent on game for their subsistence in open Last Glacial environments of Europe - were (especially in the long run) largely at the mercy of major climatic phenomena, notably fluctuations in humidity that either permitted or prohibited the growth of fodder adequate for herd-animal grazing. Processes of glacial desertification and revegetation must have been the fundamental motors forcing overall human range contraction and expansion. 
Having worked in the Upper Palaeolithic along the Atlantic façade transect from Portugal to Belgium, passing through Cantabrian Spain and southwest France, I have explored a multiplicity of human responses to the vicissitudes of Stage 2 in excavations done together with many European colleagues. I have little doubt that a biological core of the modern human populations of northern France, the British Isles, the Low Countries, Switzerland, Germany, and Scandinavia has its Tardiglacial origins in the remnant refugial populations of the Solutrean in southern France and Iberia. I would in fact argue (and I believe that many Andalusian and Portuguese colleagues would agree) that southern Iberia provided a refuge during the Last Glacial Maximum, with an apparent density of human population that - unlike the situation in Cantabrian Spain — was not matched under supposedly 'improved' conditions during the Magdalenian. (The Andalusian regional peculiarity corroborates the general observation of Gamble et al.)

The northward readvance of the Upper Magdalenian period, apparently begun just prior to the onset of the Last Glacial Interstadial ('Bølling-Allerød'), leapfrogged into particularly favourable habitats (e.g. those with pasture, topographic relief useful for shelter, game channelling and ambush, drinking water, shrubs and trees for fuel) such as the Ardennes, Creswell Crags, the Rhine-Danube headwaters area in Württemberg, the Rhine Gates, while never losing contact with the Franco-Cantabrian and Mediterranean worlds of its refugial origins (e.g. Schwendler 2004). Once established in the lower latitudes of northwest Europe, humans seem to have weathered the brunt of the Younger Dryas climatic crisis, but there were clearly territorial readjustments and a halt to the continued expansion northward, which would pick up accelerated speed and irreversibility at the onset of the Holocene Preboreal phase. This resulted in the implantation of the core of many of the Mesolithic-derived populations of Atlantic Europe as we know them today, albeit with many additions, primarily from easterly parts of the continent, over the recent millennia.

My criticisms of Gamble et al. are minor. I have always been reticent to accept the notion that radiocarbon dates are a decent proxy measure of human populations. Numbers of dates can be the consequence of archaeological budgets and philosophy. (For example, two of the excavations I have done in Cantabrian Spain - La Riera with G.A. Clark and El Mirón with M. González Morales - are together responsible for more than $90{ }^{14} \mathrm{C}$ dates, while other Cantabrian prehistorians, either for lack of funding and/or because they do not put as much stock in radicarbon dating as a chronological measure as do we Americans, have run rather fewer dates per site even in recent years.) I believe that site numbers (especially divided by millennia per culture-historic phase) can give at least a first approximation of relative regional population densities (while admitting that shifts in the number of logistical camps through time, as well as the vagaries of archaeological visibility and sampling could also distort the picture). I am not so sure that we can assume that most cave art is of Magdalenian age; it is increasingly clear, at least in Andalucía, that much more cave art than had once been suspected is of Solutrean age (see, for example, Sanchidrían et al. 2001, for the direct AMS dating of Nerja and La Pileta; Ripoll 1994, for the stratigraphic dating of Ambrosio). This may also be true of much of the open-air rock art of Portugal (notably in the Côa Valley: Zilhão 1997). Much of the art even in Lascaux (Aujoulat 2004), as well as several other major caves in southern France (e.g. Cosquer, Le Placard), is also probably of Solutrean age. I would also point out that (pace Gamble et al. and Church Hole and Geissenklösterle notwithstanding) most Upper Palaeolithic cave art is not in newly-recolonized land, except in the southern case of the Pyrenees, but rather in the refugial lands of southern Spain and Iberia (and also in southern Italy and Romania). I am less convinced than Gamble et al. as to the cultural unity and reality of the Badegoulian culture - especially with respect to Cantabrian Spain - and would be hesitant, especially with such a broadly and vaguely defined 'entity', to trace its 'movements', especially from 'the East' (see Straus \& Clark 1997). Finally, although some of my Basque colleagues would see toponymic traces of Euskera as far east as Perpignan, my Catalán colleagues would find fault with Gamble et al.'s characterization of the Basques as being in 'northeast' Iberia; they are in fact in north-central Spain and extreme southwest France, between the Upper Ebro valley, the Bay of Biscay and the Pyrenean 'Gaves'.

I look forward eagerly to sequels to this promising introductory chapter in Gamble's latest gambit - a worthy follow-on to the ambitious and exciting, if flawed, Stage 3 Project, as well as to Gamble's own seminal book, Timewalkers.

From Jean-Pierre Bocquet-Appel, CNRS, UPR 2147, 44, rue de l'Amiral Mouchez, 75014 Paris, France; bocquet-appel@ivry.cnrs.fr.

In this article, distributions of ${ }^{14} \mathrm{C}$ dates and their geographic variations within and between periods are used as proxies for the timing and intensity of 
demographic events at the Last Glacial Maximum and Late Glacial in western Europe. The approach seems robust enough to detect population events, and the signal-to-noise ratio seems reasonably high. This is a new and unexpected discovery, for which the authors must be congratulated. The authors think that the analysis of these distributions opens up possibilities for re-evaluating the relative contribution of Palaeolithic and Neolithic prehistory to the History of the present-day world, by going beyond a kind of Berlin Wall of archaeological Western thought, represented by the 'agricultural thinking' of Gordon Childe and others. It seems to me that there are, nevertheless, technical difficulties, uncertainties regarding integration of the genetic data and also omissions.

The main technical difficulty, which the authors are not unaware of, is that of sampling: a grab sample is not equal to a random sample of archaeological remains. For example, Paviland cave, which contained a few hundred tools (Campbell 1977), has yielded $54{ }^{14} \mathrm{C}$ dates (Aldhouse-Green \& Pettitt 1998) while the cave of La Madeleine, with thousands of tools from 23 main layers, has produced only $4{ }^{14} \mathrm{C}$ dates (Roque et al. 2001). For a single archaeological site/level, regional or national archaeological practice can determine tens of ${ }^{14} \mathrm{C}$ dates. The averages dates per northern Europe assemblage (Table 5) have 60 per cent more dates than the others. Beside, noise increases with the reduction in data-points. For instance, the authors based a scenario of a Solutrean refuge zone on 39 and $86{ }^{14} \mathrm{C}$ dates in France and Spain (Fig. 3), while at the same time the number of the archaeological sites goes geographically in the opposite direction with 152 and 58 sites, respectively. In addition, although the data base is not published, the Iberian ${ }^{14} \mathrm{C}$ dates come probably from a small number of sites $(<10)$ (Demars pers. comm. 2005). If true, it is difficult to qualify Iberia as a main refuge zone of western Europe. To reduce the noise, in addition to the sample size, the number of ${ }^{14} \mathrm{C}$ dates of an archaeological site should be weighted by the quantity of information that this site represents. Omitting to do so affects detection of the direction of the population event.

As far as the genetic data are concerned, there is a profusion of population models, which are contradictory and neglect to take each other into account. How, in Europe, can the Y-chromosome and mtDNA variants (Torroni et al. 2001; Richards et al. 2000) be the trace of a Late Glacial demographic expansion from the Iberian refuge zone, proceeding from northeast to southwest, without being overwritten by a Neolithic demic expansion originating from the Levant, which would be the main source for the patterning of genetic frequencies in a northwest-southeast direction (Ammerman \& Cavalli-Sforza 1984; Chikhi et al. 1998; 2002; Sokal et al. 1989; Barbujani \& Bertorelle 2001)? Contradictory models 'explain' genetic data. The link between genetic data and archaeology seems to depend on the a priori hypotheses of the researchers. This is the case with the demic expansion model. But it is also the case with the preferred model of the authors: for example, the confidence interval CI95 per cent given by the authors, for appearance of an mtDNA mutation (haplogroup V), dating the origin of the expansion (14.6 $\pm 3.6 \mathrm{ky}$, i.e. going from 21.8 to $7.4 \mathrm{ky}$ ), includes three possible peaks of population expansion (see Fig. 4), during three different periods from the Palaeolithic to Neolithic. Validations of these contradictory current genetic models leave the attentive observer in some doubt as to the chronological resolution of scenarios that can be tested against genetic data over periods of less than 20,000 years.

Among the omissions, the use of the dates-asdata is restricted to the one-dimensional distribution analysis (1D). However, this approach was extended to a 3D space-time analysis of the Neanderthal / modern human contraction/ expansion (Bocquet-Appel \& Demars 2000a). One of the co-authors (Pettitt \& Pike 2001) has even attempted to disqualify the approach with an attack that eventually turned out to be mainly founded on an over-hasty exploitation of a doubtful speleothem sample (Beck et al. 2001; Hughen et al. 2004).

Nevertheless, because of its simplicity and its consequences, the detection of a population signal from distributions of ${ }^{14} \mathrm{C}$ dates seems to me to be one of the major archaeological innovations of recent years.

From Peter A. Underhill, Department of Genetics \& Roy King, Department of Psychiatry \& Behavioral Sciences, Stanford University, Stanford, CA 94305, USA; under@stanford.edu.

Perhaps the most surprising result of this case study involving the analysis of calibrated radiocarbon-dated material from western Europe is the remarkable early date for the initial expansion from refugia in Cantabria and southwest France (Aquitaine) at 19.5-16 ka BP. The occurrence of these events is more contemporaneous with the Last Glacial Maximum rather than the onset of Holocene warming. In addition it is obviously independent of the earliest phases of the transition to agriculture in the Middle East.

Genetic signatures of these prehistoric events are recorded in the patterns of diversity sequestered in the contemporary gene pool, especially those within the 
non-recombining components of the haploid mtDNA (Achilli et al. 2004) and Y-chromosome genomes (Semino et al. 2000; Rootsi et al. 2004). The lower effective population size of these haploid systems results in more rapid between-population divergence rates relative to those displayed in the autosomal component of the human genome. The framework of these haploid genealogies is now richly detailed with considerable sequential diversification that have both unequivocal hierarchy and strong geographic structure. Thus the phylogeographic approach of genetic analysis offers more insight than simple haplogroup summary statistics and frequency distributions that marginalize low frequency but evolutionarily important lineages.

The radiocarbon dates that are representative of an unanticipated early population growth and northwards expansion of complex hunter-gathers into western Europe during periods of presumed climatic adversity help explain the paradox of relatively high genetic variance observed in certain Y-chromosome haplogroups. This is in contrast to simulation models (Edmonds et al. 2004) that show that expanding wave fronts have low genetic variance relative to their source regions. Such models are consistent with supportive empirical genetic evidence of wave-front phenomena detected in patterns of microsatellite variance associated with Y-chromosome haplogroup J2 lineages that display a statistically-significant decline in diversity (but not frequency) in a south-north trend across Anatolia (Cinnioglu et al. 2004). Moreover, such phylogeographic wave front patterns are congruent with diagnostic material culture characteristic of subsequent Neolithic expansions and settlements across Turkey (Roberts 2002) and into the Greek Thessalian plain (King \& Underhill 2002). It is important to recognize that the earlier episodes of population growth seen in western Europe refugia would lead to an increase in diversity relative to the alternative situations of either: a) constant population size circumstances where amounts of diversity are maintained at lower levels owing to an equilibrium between the appearance and extinction of mutations; or b) more recent radiations reflecting the migration of agriculturalists approaching the periphery of their distribution.

In conclusion, it should be emphasized that the authors have skilfully modelled a relatively simple demographic scenario, namely the repopulation of a previously vacant landscape that bears analogies to island colonization and biogeography. For more complicated situations like that of south and central Asia where archaeological data are sparser, the picture may be not as straightforward. Phylogeographic studies of well-differentiated haploid systems are likely, however, to help illuminate these inherently more complex histories.

From Rupert Housley, Department of Archaeology, University of Glasgow, Glasgow, G12 8QQ, Scotland, UK; r.housley@archaeology.gla.ac.uk.

This latest contribution by Gamble and his colleagues is one of a growing number of papers (e.g. Blackwell \& Buck 2003; Lourandos \& David 2002; Gamble et al. 2004; Holdaway \& Porch 1995; Housley et al. 1997; Rick 1987; Ross 2001) that in the last two decades have used radiocarbon 'dates-as-data' as a proxy for population history or as a means to explore patterns of population dispersal on a regional or sub-continental scale. Significantly, they attempt to distance the study of population history from the twin influences represented by the agriculturalist 'wave of advance' and the spread of the major language groups. In this context it is worth reflecting on a few points.

The current article revisits many of the issues that the same authors (excluding Hazelwood) addressed in a previous paper (Gamble et al. 2004). My first thoughts were that it could be informative to see if the pattern of re-colonization changed as new data are added, for in such papers the veracity of the inferences typically depend on the quality of the data and the applied mode of analysis. When these change the results often reveal the robustness of the data set. I noted new data (227 new ${ }^{14} \mathrm{C}$ determinations) had been incorporated but with what outcome? Surprisingly none whatsoever, if the probability curves presented in Figure 2, and figure 1 of Gamble et al. (2004, 248 ), are to be believed. Taken at face value this may reflect the robustness of the data set, but since Figures 3 and 6 of this article are identical to figures 2 and 4 of Gamble et al. (2004, 249 \& 251) I suspect not. Rather it indicates no new analyses were undertaken using the larger data set. This is unfortunate in that it is thus not possible to assess the robustness of the identified patterning. Auditing the data base has removed twothirds of the entries. (This is not a criticism, for I fully concur that quality must be given primacy.) It is commonly informative to examine the impact of such data cleaning given the likelihood that such processing will not have impacted uniformly across all parts of the data set. Whilst it is probably fair to acknowledge that the broad patterns presented may be sound, the detail may have some shortcomings. The mixed messages coming from the demic history of Iberia are probably the result of sampling biases in the data base.

Whether the main population expansion and geographical dispersal from south to north associ- 
ated with event 3 is correlated with - or precedes - climatic amelioration is, to my mind, an important issue. Gamble and colleagues are probably safe in using the GRIP $\delta^{18} \mathrm{O}$ curve as the basis for inferring climatic events in their study region. Proxy climate data from localities linked by the Gulfstream, i.e. the Greenland ice cores, the marine records from the Cariaco Trench (Bard et al. 2004; Hughen et al. 2004) and the Portuguese coast (de Abreu et al. 2003) seem to correlate well and probably hold good for the maritime regions of western Europe (van Andel 2005). The extent to which this climatic regime would be valid if the authors were to extend their coverage farther east is, however, much more contentious.

In the past, various authors (e.g. Blockley et al. 2000; Dolukhanov 1979; Otte 1997) have argued that major demic expansion and re-colonization of the unpopulated regions of western Europe only began as the climate ameliorated at the beginning of the Lateglacial Interstadial (GI-1e: Bølling). The findings of Gamble et al. strongly suggest the contrary, placing the demic commencement in the preceding Stadial GS-2a, thereby emphasizing cultural adaptive strategies as being of more importance over environmental determinist factors. Given recent discussion of the highly successful culturally-based cold adaptation of the Gravettian and its contrast to the preceding Aurignacian mode of adaptation (Davies \& Gollop 2003), this re-examination of the climate preferences of the Late Magdalenian ATU2 is both timely and to be welcomed. Changes in our view of the impact of the Last Glacial Maximum (LGM) on the demography of both western and eastern Europe (e.g. Ross 2001) using the dates-as-data approach mean that some of the long-held assumptions may be ripe for re-evaluation.

My final observation concerns the Badegoulian and the way this relatively understudied ATU2 has started to take on a prominence not previously accorded. The combination of a low density of sites over an extensive geographical distribution including western central Europe; a chronological range centred on the period immediately after the Pleniglacial; an inferred origin in the east but association with the early pioneer stages of the demic expansion in population event 2 (Street \& Terberger 1999; 2000; Terberger \& Street 2002); a generalized technology analogous in both function and form to the Aurignacian; and the possible link to the mtDNA haplogroups $\mathrm{H}$ and pre- $\mathrm{V}$, suggests it may have played a much larger role than has previously been realized. Perhaps in the near future we may begin better to understand the nature, and appreciate the importance, of low-level spatially extensive modes of population mobility in the Upper Palaeolithic.

\section{Reply}

We thank all those who responded for their comments. We are particularly pleased that such strong support for our synthesis comes from the disciplines of archaeology, molecular genetics, chronometric dating and human demography since our intention was interdisciplinary. We also appear to be pushing at an open door with our criticisms of historical linguistics and the distortions that arise from applying inappropriate agricultural models to the Palaeolithic and especially the Late Glacial. As a result we welcome this recognition since it bears directly on a crucial argument in the interpretation of the last 50,000 years. Those who look back from the villages and cities of the Holocene identify the emergence of 'society as we know it' (Runciman 2005, 137) with the appearance of settled life. This is the revolution that made us who we are today (Renfrew 2001). The earlier human revolution, that either was (Klein 1995) or wasn't one (McBrearty \& Brooks 2000), is from this backward-looking perspective only of interest in that it represents the acquisition of skills and capacities, notably language, art and symbolic-based action, but not their implementation. Otherwise, so the argument goes, there would not be a 30,000-year wait before agriculture, towns and civilization appeared. By contrast, our Late Glacial synthesis looks forward to these developments rather than backwards to their supposed origins. We have no starting point in an earlier Human revolution and in the evidence for population history and dispersal find it difficult to support a Holocene origin for who we are, either socially, cognitively or genetically.

Straus's comments are particularly pertinent in this regard and demonstrate the importance of not approaching the archaeology of human society with a teleological mindset. We agree with him that southern Iberia provided a refugium at the LGM although we are increasingly left wondering what exactly is the LGM. Some years ago it was possible to identify it as 18,000 uncal bp (CLIMAP 1976) while now the maximum extent of the Fennoscandian ice sheet is 22,000 cal вр (Lowe \& Walker 1997). But more important is its duration and supposed impact on the environment and human populations. Increasingly it appears from radiocarbon data bases such as those of the Stage 3 and S2AGES Projects that the numbers of people in Europe, particularly north of the continental divide, was extremely small. It is only in GS-2a which we report on here as our third population event that there is any evidence that population numbers rose. This being the case, another of the traditional correlations 
between climate minima / ice maxima and the contraction of humans into refugium in Europe needs to be questioned (Soffer \& Gamble 1990).

Consequently the issues raised by Straus, Bocquet-Appel and Housley regarding the relevance and use of radiocarbon dates as demographic proxies are most apposite. Since we had cautioned readers to interpret our data in very broad terms, we obviously acknowledge Straus's reticence 'to accept the notion that radiocarbon dates are a decent proxy measure of human populations'. We hope, however, that we have made clear that amidst the noise of contemporary archaeological concerns - who has the facilities, resources and agenda to date relevant sites - that some coarse structure pertaining to antiquity will be apparent. To use the words of Housley 'the broad patterns presented may be sound, [but] the detail may have some shortcomings.' In essence we are attempting his 'first approximation of relative regional population densities' and emphasize the term 'approximation'. We also take his point about our assumptions that cave art is usually Magdalenian, but advance the recent work by d'Errico et al. (2001) which, as a grab sample of dated art, does reveal a clear peak of dates corresponding to the Magdalenian. While the issue is obviously still open, we predict that there will be inevitably more Magdalenian art than Solutrean.

The main concerns in Straus's, Bocquet-Appel's and Housley's comments crystallize into how much contemporary noise contamination is in our data and how it is distributed; resolving these issues should demonstrate exactly how the resulting demographic proxies are affected. Straus notes how the number of ${ }^{14} \mathrm{C}$ determinations for Iberian sites varies considerably between prehistorians, and Bocquet-Appel compares Paviland Cave (small archaeological assemblages, large number of dates) to La Madeleine (vice versa). It should be noted, however, that the S2AGES data base contains only two ${ }^{14} \mathrm{C}$ determinations for Paviland, both on human remains. We certainly agree that assemblage variability needs to be used to qualify our conclusions derived from the pattern of dates (see pages 199-200 in respect of Table 6, for example), and are already exploring ways of how we might address this major question (Davies et al. in prep.).

One of us (Pettitt 2005) has previously questioned the Stage Three Project with regard to noise contamination, and as a result the S2AGES data base adopted a more explicit approach; first by auditing the data base according to agreed criteria (Pettitt et al. 2003) thereby minimizing noise, and second by comparing the distribution of radiocarbon determinations by region (Table 5). This revealed a very broad similarity of dates per assemblage for the relevant countries of western Europe. In the latter case, while we acknowledge that certain sites such as Gough's Cave are relatively welldated and will therefore 'bump up' our graphs and sites such as La Madeleine are, perhaps surprisingly, poorly-dated, their individual effect on the overall data base is low and, we suggest, not distorting the broad picture in any major way. We are unclear why Bocquet-Appel believes that the average number of dates per northern European assemblage (Table 5) unbalances the data base: the figure for Belgium and The Netherlands (1.89 dates/assemblage) compares with 1.5 to 1.9 for more southerly countries including Austria, France, Portugal and Spain, and the highest numbers are actually found in Germany and Switzerland. We suspect that the cause of Bocquet-Appel's concern here is the unexpectedly high ratio of 2.23 for the British Isles, which is caused by ambitious dating programmes for many sites, including Gough's Cave and Howick. It is worth noting that we also have richly-dated French sites in our data base, such as La Salpêtrière, La Ferrassie and Abri Pataud. Given the general frequencies, however, we do not believe these differential date:site ratios are a serious problem.

We assume that Bocquet-Appel's figures of 152 Solutrean sites for France, and 58 ones for Spain/ Iberia include undated as well as dated localities. The S2AGES data base contains 25 dated Solutrean sites from Spain (plus another 2 probable ones), and 5 from Portugal (plus another 3 probable/ possible ones). In comparison, the number of dated French Solutrean sites in our data base is 16 (plus another site that can probably be attributed to this ATU2 also). We should probably not assume too much from these relative proportions of dated sites at this stage: there are many reasons to explain the discrepancy. What is evident, however, is that the Solutrean is remarkably poorly dated in radiometric terms: when the 149 Solutrean dates in the S2AGES data base are audited, only 17 are found to be of acceptable quality (from 6 assemblages)! Straus will be relieved to learn that 7 out of the 14 Solutrean dates from La Riera in our data base passed our audit criteria, but elsewhere clearly much (re)dating needs to be done.

Auditing of the data base, using uniform criteria, has allowed us to examine the radiometric age record of western Europe at varying levels of confidence, by including or excluding dates that have failed the audit. What difference to the spatio-temporal patterning of our sites and assemblages does their exclusion make? How many dated sites disappear after the application of auditing? In addition, our spatial scales of analysis are variable, with the data base being analyzed at 
intersite (regional) and intrasite (assemblage) scales. In these ways, we aim to address questions of noise in our data sets.

As our model seeks to use chronological data in a spatial context, we are unclear as to how our approach is 'one-dimensional' as it shares goals and a similar methodological underpinning to Bocquet-Appel's own work, which he describes as a '3D space-time analysis'. Pettitt \& Pike (2001) identified a number of weaknesses in the 3D space-time analysis, and drew attention to problems with accuracy and precision in the period $>20,000$ BP which questioned the results of Bocquet-Appel and Demars. Speleothem data from the Bahamas were used to illustrate such problems, and therefore were not an interpretative crux.

We welcome Housley's comments on climatic correlations and soundly concur that the previously low-profile Badegoulian deserves considerably more attention. It is, as he suggests, that through such faint archaeological signatures we will come to understand more about patterns of land use and dispersal. As an example, and in reply to Housley's plea for additional analysis we present here an audited account of Population events 3 to 5, using the final version of the data base (Fig. 8). As can be seen, the patterning in the (unaudited) data set is robust enough to survive augmentation in the number of dates.

Nevertheless, when auditing criteria were applied to the 2483 usable $14 \mathrm{C}$ dates in the S2AGES data base from western Europe, only 982 (40 per cent) passed the audit criteria on grounds of both dating methodology and archaeological reliability. These 982 dates derived from 415 assemblages. Many dates still cited in the literature were obtained more than thirty years ago, when research priorities were geared towards chronological range-finding (often at the intrasite scale) rather than obtaining a high-resolution intersite spatio-temporal picture. Such dates frequently fell foul of our auditing processes. The now widespread application of AMS ${ }^{14} \mathrm{C}$ techniques has made us much more sensitive to the relationship of radiocarbon samples to their (supposed) archaeological contexts, and future ${ }^{14} \mathrm{C}$ dating programmes will of necessity have to have a strategic awareness of what the dating of selected samples will contribute to our broader understanding of Late Glacial archaeology.
We agree with Bocquet-Appel that genetic data suffer from chronological imprecision. That is why we suggested here an alternative to simply trying to read prehistoric dispersals straight from the DNA sequences (an approach still taken by some classicallytrained population geneticists, who run off various crude summaries of the data and are then inclined to complain that there's nothing to see).

Rather, we believe that genetic data can be used to test distinct dispersal models, despite the lack of precision of genetic dating, by making use of a radiocarbon-based archaeological framework. For example: if we suspect from the archaeology that dispersals may have taken place in Europe at around $15 \mathrm{ka}$ and $8 \mathrm{ka}$, to what extent have each of these putative processes left a signature in the genetic record? Furthermore, phylogeographic explanations take into account not only genetic age estimates - imprecise as they are - but also the distributions of lineages, which often exhibit striking patterns, as Underhill remarks. From such analyses, it seems highly likely that the majority of European mtDNA and Y-chromosome lineages are the result of Late Glacial expansions from south to north, although clearly any from the southeast may be conflated with later Neolithic movements.

But there is no contradiction between identifying signals associated with both Late Glacial expansions from the southwest of Europe and Neolithic dispersals from the Near East. As Cavalli-Sforza and his colleagues showed us long ago, distinct patterns can be teased out of even classical genetic marker dis- 
tributions, and the data and methods we have at our disposal today are far more powerful than what he had to work with then. There is a clear signal in the mtDNA $\mathrm{V}, \mathrm{H} 1$ and $\mathrm{H} 3$ haplogroups of a large-scale expansion centred geographically on the southwest of Europe and most likely originating around 11-16 ka BP; and smaller signals from several other mtDNA haplogroups of a Neolithic dispersal from the Near East. Similar signals have been detected in Y-chromosome patterns. And we do not think that these interpretations depend critically on our prior expectations - remember that when the genetic data were first suggested to support Late Glacial expansions in the mid-1990s, the dominant view in population genetics was that the major signal was Neolithic. This came as something of a surprise and seems to have been resisted by some ever since.

\section{References}

Achilli, A., C. Rengo, C. Magri, V. Battaglia, S. Olivieri, R. Scozzari, F. Cruciani, M. Zeviani, E. Briem, V. Carelli, P. Moral, J.-M. Dugoujon, U. Roostalu, E.-L. Loogväli, T. Kivisild, H.-J. Bandelt, M. Richards, R. Villems, A.S. Santachiara-Benerecetti, O. Semino \& A. Torroni, 2004. The molecular dissection of mtDNA haplogroup $\mathrm{H}$ confirms that the Franco-Cantabrian glacial refuge was a major source for the European gene pool. American Journal of Human Genetics 75, 910-18.

Aldhouse-Green, S.H.R. \& P.B. Pettitt, 1998. Paviland Cave: contextualizing the Red Lady. Antiquity 72(278), 756-72.

Alexandri, A., 1995. The origins of meaning, in Interpreting Archaeology: Finding Meaning in the Past, eds. I. Hodder, M. Shanks, A. Alexandri, V. Buchli, J. Carman, J. Last \& G. Lucas. London: Routledge, 57-67.

Ammerman, A.J. \& L.L. Cavalli-Sforza, 1973. A population model for the diffusion of early farming in Europe, in The Explanation of Culture Change: Models in Prehistory, ed. C. Renfrew. London: Duckworth, 343-58.

Ammerman, A. \& L.L. Cavalli-Sforza, 1979. The wave of advance model for the spread of agriculture in Europe, in Transformations: Mathematical Approcahes to Culture change, eds. C. Renfrew \& K.L. Cooke. London: Academic Press, 275-94.

Ammerman, A.J. \& L.L. Cavalli-Sforza, 1984. The Neolithic Transition and the Genetics of Populations in Europe. Princeton (NJ): Princeton University Press.

Anderson, D.G. \& J.C. Gillam, 2000. Paleoindian colonization of the Americas: implications from an examination of physiography, demography, and artifact distribution. American Antiquity 65, 43-66.

Aujoulat, N., 2004. Lascaux: le geste, l'espace et le temps. Paris. Éditions du Seuil.

Bailey, G. (ed.), 1997. Klithi: Archaeology of a Late Glacial Landscape in Epirus (Northwest Greece). (McDonald Institute Monographs.) Cambridge: McDonald Institute for Archaeological Research.
Balter, M., 2003. Early date for the birth of Indo-European languages. Science 302, 1490-91.

Bandelt, H.-J., V. Macaulay \& M. Richards, 2002. What molecules can't tell us about the spread of languages and the Neolithic, in Examining the Farming/Language Dispersal Hypothesis, eds. P. Bellwood \& C. Renfrew. (McDonald Institute Monographs.) Cambridge: McDonald Institute for Archaeological Research, 99-107.

Bar-Yosef, O., 1998. On the nature of transitions: the Middle to Upper Palaeolithic and the Neolithic Revolution. Cambridge Archaeological Journal 8(2), 141-63.

Barbujani, G. \& G. Bertorelle, 2001. Genetics and the population history of Europe. Proceedings of the National Academy of Science of the USA 98(1), 22-5.

Barbujani, G. \& R.R. Sokal, 1990. Zones of sharp genetic change in Europe are also linguistic boundaries. Proceedings of the National Academy of Science of the USA 87, 1816-19.

Bard, E., F. Rostek \& G. Ménot-Combes, 2004. Paleoclimate: a better radiocarbon clock. Science 303, 178-9.

Barton, R.N.E., 1999. Colonization and resettlement of Europe in the lateglacial: a view from the western periphery. Folia Quaternaria 70, 71-86.

Barton, R.N.E., R.M. Jacobi, D. Stapert \& M. Street, 2003. The Late-glacial reoccupation of the British Isles and the Creswellian. Journal of Quaternary Science 18, 631-43.

Beck, J.W., D.A. Richards, R.L. Edwards, B.W. Silverman, P.L. Smart, D.J. Donahue, S. Hererra-Osterheld, G.S. Burr, L. Calsoyas, A.J.T. Jull \& D. Biddulph, 2001. Extremely large variations of atmospheric ${ }^{14} \mathrm{C}$ concentration during the Last Glacial Period. Science 292, 245-8.

Bellwood, P. \& C. Renfrew (eds.), 2002. Examining the Farming/Language Dispersal Hypothesis. (McDonald Institute Monographs.) Cambridge: McDonald Institute for Archaeological Research.

Binford, L.R., 2001. Constructing Frames of Reference: an Analytical Method for Archaeological Theory Building using Ethnographic and Environmental Datasets. Berkeley (CA): University of California Press.

Björck, S., M.J.C. Walker, L.C. Cwynar, S. Johnsen, K.-L. Knudsen, J.J. Lowe \& B. Wohlfarth, 1998. An event stratigraphy for the Last Termination in the North Atlantic region based on the Greenland ice-core record: a proposal by the INTIMATE group. Journal of Quaternary Science 13, 283-92.

Blackwell, P.G. \& C.E. Buck, 2003. The Late Glacial human reoccupation of north-western Europe: new approaches to space-time modelling. Antiquity 77, 232-40.

Blockley, S.P.E., R.E. Donahue \& A.M. Pollard, 2000. Radiocarbon calibration and Late Glacial occupation in northwest Europe. Antiquity 74, 112-21.

Boast, R. 1997. A small company of actors: a critique of style. Journal of Material Culture 2, 173-98.

Bocquet-Appel, J.P. \& P.Y. Demars, 2000a. Neanderthal contraction and Modern human colonization of Europe. Antiquity 74, 544-52.

Bocquet-Appel, J.-P. \& P.-Y. Demars, 2000b. Population kinetics in the Upper Palaeolithic in western Europe. Journal of Archaeological Science 27, 551-70. 
Bordes, F., 1968. The Old Stone Age. London: Weidenfeld \& Nicholson.

Campbell, J.B., 1977. The Upper Palaeolithic of Britain. Oxford: Oxford University Press.

Cauvin, J., 2000. The Birth of the Gods and the Origins of Agriculture. Cambridge: Cambridge University Press.

Cavalli-Sforza, L.L. \& F. Cavalli-Sforza, 1995. The Great Human Diasporas: the History of Diversity and Evolution. Reading (MA): Perseus Books.

Cavalli-Sforza, L.L., A. Piazza, P. Menozzi \& J. Mountain, 1988. Reconstruction of human evolution: bringing together genetic, archaeological, and linguistic data. Proceedings of the National Academy of Sciences of the USA 85, 6002-6.

Cavalli-Sforza, L., P. Menozzi \& A. Piazza, 1994. History and Geography of Human Genes. Princeton (NJ): Princeton University Press.

Charles, R., 1996. Back into the North: the radiocarbon evidence for the human recolonization of the north-west Ardennes after the last glacial maximum. Proceedings of the Prehistoric Society 62, 1-19.

Chatfield, C., 1980. The Analysis of Time Series: an Introduction. 2nd edition. London: Chapman and Hall.

Chikhi, L., G. Destro-Bisol, G. Bertorelle, V. Pascali \& G. Barbujani, 1998. Clines of nuclear DNA markers suggest a largely Neolithic ancestry of the European gene pool. Proceedings of the National Academy of Sciences of the USA 95, 9053-8.

Chikhi, L., R.A. Nichols, G. Barbujani \& M.A. Beaumont, 2002. Y genetic data support the Neolithic demic diffusion model. Proceedings of the National Academy of Sciences of the USA 99, 11,008-13.

Childe, V.G., 1925. The Dawn of European Civilization. London: Cape.

Cinnioglu, C., R. King, T. Kivisild, E. Kalfoglu, S. Atasoy, G.L. Cavalleri, A.S. Lillie, C.C. Roseman, A.A. Lin, K. Prince, P.J. Oefner, P. Shen, O. Semino, L.L. CavalliSforza \& P.A. Underhill, 2004. Excavating Y-chromosome haplotype strata in Anatolia. American Journal of Human Genetics 114, 127-48.

Clark, J.G.D., 1975. The Earlier Stone Age Settlement of Scandanavia. Cambridge: Cambridge University Press.

Clarke, D.L., 1968. Analytical Archaeology. London: Methuen.

CLIMAP, 1976. The surface of ice age earth. Science 191, 1131-7.

Coles, B., 1998. Doggerland: a speculative survey. Proceedings of the Prehistoric Society 64, 45-81.

Constandse-Westermann, T.S. \& R.R. Newell, 1991. Social and biological aspects of the western European mesolithic population structure: a comparison with the demography of North American Indians, in The Mesolithic in Europe, ed. C. Bonsall. Edinburgh: Edinburgh University Press, 106-15.

David, N., 1973. On Upper Palaeolithic society, ecology, and technological change: the Noaillian case, in The Explanation of Culture Change: Models in Prehistory, ed. C. Renfrew. London: Duckworth, 277-303.

Davidson, I. \& W. Noble, 1993. Tools and language in human evolution, in Tools, Language and Cognition in Human
Evolution, eds. K.R. Gibson \& T. Ingold. Cambridge: Cambridge University Press, 363-88.

Davies, W., 2001. A very model of a modern human industry: new perspectives on the origins and spread of the Aurignacian in Europe. Proceedings of the Prehistoric Society 67, 195-217.

Davies, W. \& P. Gollop, 2003. The human presence in Europe during the Last Glacial period II. Climate tolerance and climate preferences of mid- and late glacial hominids, in Neanderthals and Modern Humans in the European Landscape during the Last Glaciation, eds. T. van Andel \& W. Davies. (McDonald Institute Monographs.) Cambridge: McDonald Institute for Archaeological Research, 131-46.

Davies, W., P. Valdes, C.A. Ross \& T. van Andel, 2003. The human presence in Europe during the last glacial period III: site clusters, regional climates and resource attractions, in Neanderthals and Modern Humans in the European Landscape during the Last Glaciation, eds. T. van Andel \& W. Davies. (McDonald Institute Monographs.) Cambridge: McDonald Institute for Archaeological Research, 191-220.

Davies, W., C. Gamble, P. Pettitt \& M. Richards (eds.), in prep. Founders and Farmers: a Population History of Europe and the Near East, 20,000-8000 Years Ago. Cambridge: Cambridge University Press.

de Abreu, L., N.J. Shackleton, J. Schönfeld, M. Hall \& M. Chapman, 2003. Millennial-scale oceanic climate variability off the western Iberian margin during the last two glacial periods. Marine Geology 196, 1-20.

Demars, P.-Y., 1996. Démographie et occupation de l'espace au Paléolithique supérieur et au Mésolithique en France. Préhistoire Européenne 8, 3-26.

d'Errico, F., M. vanhaeren, M.-F. Sánchez Goñi, F. Grousset, H. Valladas \& J.-P. Rigaud, 2001. Les possibles relations entre l'art des cavernes et la variabilité climatique rapide de la dernière période glaciaire, in Datation: XXIe rencontres internationales d'archéologie et d'histoire d'Antibes, eds. J.-N. Barrandon, P. Guibert \& P. Michel. Antibes: Éditions APDCA, 333-47.

Dixon, R.M.W., 1997. The Rise and Fall of Languages. Cambridge: Cambridge University Press.

Djindjian, F., 1994. L'influence des frontières naturelles dans les déplacements des chasseurs-cueilleurs au würm récent. Preistoria Alpina 28, 7-28.

Djindjian, F., J. Koslowski \& M. Otte, 1999. Le Paléolithique supérieur en Europe. Paris: Armand Colin.

Dolukhanov, P., 1979. Evolution des systèmes éco-sociaux en Europe durant le pléistocène récent et le début de l'holocène, in La fin des temps glaciaires en Europe, ed. D. de Sonneville-Bordes. Paris: CNRS, 869-76.

Edmonds, C., A. Lillie \& L. Cavalli-Sforza, 2004. Mutations arising in the wave front of an expanding population. Proceedings of the National Academy of Sciences of the USA 101, 975-9.

Eriksen, B., 1991. Change and Continuity in a Prehistoric Hunter-gatherer Society: a Study of Cultural Adaptation in Late Glacial-Early Post-glacial Southwestern Germany. Tübingen: Archaeologica Venatoria 12. 
Eriksen, B., 1996. Regional variation in Late Pleistocene subsistence strategies, southern Scandinavian reindeer hunters in a European context, in The Earliest Settlement of Scandinavia and its Relationship with Neighbouring Areas, ed. L. Larsson. (Acta Archaeologica Lundensia 24.) Stockholm: Almquist \& Wiksell International, 7-21.

Floss, H., 2000. Le couloir Rhin-Saône-Rhône: axe de communication au Tardiglaciaire?, in Les derniers chasseurs-cueilleurs d l'Europe occidentale: Actes du colloque international de Besançon 1998. Presses Universitaires Franc-Comtoises 313 à 321 (Annales Littéraires, 699; Série Environnement, sociétés et archéologie, 1.), 313-21.

Foley, R.A., 1994. Speciation, extinction and climatic change in hominid evolution. Journal of Human Evolution 26, 275-89.

Gamble, C.S., 1983. Culture and society in the Upper Palaeolithic of Europe, in Hunter-gatherer Economy in Prehistory, ed. G.N. Bailey. Cambridge: Cambridge University Press, 201-11.

Gamble, C.S., 1986. The Palaeolithic Settlement of Europe. Cambridge: Cambridge University Press.

Gamble, C.S., 1999. The Palaeolithic Societies of Europe. Cambridge: Cambridge University Press.

Gamble, C.S., 2001. Archaeology: the Basics. London: Routledge.

Gamble, C.S. \& E.K. Gittins, 2004. Social archaeology and origins research: a Palaeolithic perspective, in $A$ Companion to Social Archaeology, eds. L. Meskell \& R. Preucell. Oxford: Blackwell, 96-118.

Gamble, C.S., W. Davies, P. Pettitt \& M. Richards, 2004. Climate change and evolving human diversity in Europe during the last glacial. Philosophical Transactions of the Royal Society Biological Sciences 359, 243-54.

Garrod, D.A.E., 1926. The Upper Palaeolithic Age in Britain. Oxford: Clarendon Press.

Gilman, A., 1984. Explaining the Upper Palaeolithic revolution, in Marxist Perspectives in Archaeology, ed. M. Spriggs. Cambridge: Cambridge University Press, 115-26.

Gray, R.D. \& Q.D. Atkinson, 2003. Language-tree divergence times support the Anatolian theory of Indo-European origin. Nature 426, 435-9.

Hazelwood, L. \& J. Steele, 2004. Spatial dynamics of human dispersals; constraints on modelling and archaeological validation. Journal of Archaeological Science 31, 669-79.

Henry, D.O., 1995. Prehistoric Cultural Ecology and Evolution: Insights from Southern Jordan. New York (NY): Plenum.

Hewitt, G.M., 1996. Some genetic consequences of ice ages, and their role in divergence and speciation. Biological Journal of the Linnean Society 58, 247-76.

Hewitt, G.M., 1999. Post-glacial re-colonization of European biota. Biological Journal of the Linnean Society 68, 87-112.

Higgs, E.S. (ed.), 1975. Palaeoeconomy. Cambridge: Cambridge University Press.
Holdaway, S. \& N. Porch, 1995. Cyclical patterns in the pleistocene human occupation of southwest Tasmania. Archaeology in Oceania 30, 74-82.

Housley, R.A., C.S. Gamble, M. Street \& P. Pettitt, 1997. Radiocarbon evidence for the Late Glacial human recolonization of northern Europe. Proceedings of the Prehistoric Society 63, 25-54.

Hughen, K., S. Lehman, J. Southon, J. Overpeck, O. Marchal, C. Herring \& J. Turnbull, 2004. ${ }^{14} \mathrm{C}$ Activity and global carbon cycle changes over the past 50,000 years. Science 303, 202-6.

Indreko, R., 1948. Origin and area of settlement of the FennoUgrian peoples. Science in Exile. Scholar 1, 3-24.

Ingold, T., 2000. The Perception of the Environment: Essays in Livelihood, Dwelling and Skill. London: Routledge.

Jochim, M.A., 1983. Palaeolithic cave art in ecological perspective, in Hunter-gatherer Economy in Prehistory, ed. G.N. Bailey. Cambridge: Cambridge University Press, 212-19.

Jochim, M.A., 1987. Late pleistocene refugia in Europe, in The Pleistocene Old World: Regional Perspectives, ed. O. Soffer. New York (NY): Plenum, 317-31.

Jochim, M.A., C. Herhahn \& H. Starr, 1999. The Magdalenian colonization of southern Germany. American Anthropologist 101, 129-42.

Jones, R., 1977. The Tasmanian paradox, in Stone Tools as Cultural Markers, ed. R.V.S.Wright. Canberra: Australian Institute of Aboriginal Studies, 189-204.

Jones, S., 1997. The Archaeology of Ethnicity: Constructing Identities in the Past and Present. London: Routledge.

King, R. \& P.A. Underhill, 2002. Congruent distribution of Neolithic painted pottery and ceramic figurines with Y-chromosome lineages. Antiquity 76, 707-14.

Klein, R.G., 1995. Anatomy, behavior, and modern human origins. Journal of World Prehistory 9, 167-98.

Laville, H., J.-P. Rigaud \& J.R. Sackett, 1980. Rock Shelters of the Périgord. New York (NY): Academic Press.

Leroi-Gourhan, A., 1993. Gesture and Speech. Cambridge (MA): MIT Press.

Lewis-Williams, D., 2003. The Mind in the Cave. London: Thames \& Hudson.

Loogväli, E.L., U. Roostalu, B.A. Malyarchuk, M.V. Derenko, T. Kivisild, E. Metspalu, K. Tambets, M. Reidla, H.-V. Tolk, J. Parik, E. Pennarun, S. Laos, A. Lunkina, M. Golubenko, L. Barac, M. Pericic, O.P. Balanovsky, V. Vladislava Gusar, E.K. Khusnutdinova, V. Stepanov, V. Puzyrev, P. Rudan, E.V. Balanovska, E. Grechanina, C. Richard, J. P. Moisan, A. Chaventré, N.P. Anagnou, K.I. Pappa, E.N. Michalodimitrakis, M. Claustres, M. Gölge, I. Mikerezi, E. Usanga \& R. Villems, 2004. Disuniting uniformity: a pied cladistic canvas of mtDNA haplogroup $\mathrm{H}$ in Eurasia. Molecular Biology and Evolution 21, 2012-21.

Lourandos, H. \& B. David, 2002. Long-term archaeological and environmental trends: a comparison from Late Pleistocene Australia, in Bridging Wallace's line: the Environmental and Cultural History and Dynamics of the SE-Asia-Australian Region, eds. P. Kershaw, B. David, N. Tapper, D. Penny \& J. Brown. (Advances in Ge- 
Archaeological and Genetic Foundations of the European Population during the Late Glacial

oecology 34.) Reiskirchen: Catena, 307-38.

Lowe, J.J. \& M.J.C. Walker, 1997. Reconstructing Quaternary Environments. Harlow: Longman.

Lowe, J.J., W.Z. Hoek \& INTIMATE group, 2001. Inter-regional correlation of palaeoclimatic records for the Last Glacial-Interglacial transition: a protocol for improved precision recommended by the INTIMATE project group. Quaternary Scence Reviews 20, 1175-87.

McBrearty, S. \& A.S. Brooks, 2000. The revolution that wasn't: a new interpretation of the origin of modern humans. Journal of Human Evolution 39, 453-563.

McEvoy, B., M. Richards, P. Forster \& D.G. Bradley, 2004. The longue durée of genetic ancestry: multiple genetic marker systems and Celtic origins on the Atlantic façade of Europe. American Journal of Human Genetics 75, 693-702.

Mellars, P., 1996. The emergence of biologically modern populations in Europe: a social and cultural 'revolution'?, in Evolution of Social Behaviour Patterns in Primates and Man, eds. W.G. Runciman, J. Maynard-Smith \& R.I.M. Dunbar. Oxford: Oxford University Press, 179-201.

Mellars, P. \& K. Gibson (eds.), 1996. Modelling the Early Human Mind. (McDonald Institute Monographs.) Cambridge: McDonald Institute for Archaeological Research.

Meskell, L. \& R. Preucell (eds.), 2004. A Companion to Social Archaeology. Oxford: Blackwell.

Mithen, S., 1996. The Prehistory of the Mind. London: Thames \& Hudson.

Moore, J., 2001. Evaluating five models of human colonization. American Anthropologist 103, 395-408.

Noble, W. \& I. Davidson, 1996. Human Evolution, Language and Mind. Cambridge: Cambridge University Press.

Otte, M., 1997. Paléolithique final du Nord-Ouest, migrations et saisons, in Le Tardiglaciare en Europe du NordOuest, eds. J.-P. Fagnart \& A. Thévenin. Paris: CTHS, 353-66.

Pereira, L., M. Richards, A. Goios, A. Alonso, C. Albarran, O. Garcia, D.M. Behar, M. Golge, J. Hatina, L. Al-Gazali, D.G. Bradley, V. Macaulay \& A. Amorim, 2005. Highresolution mtDNA evidence for the late-glacial resettlement of Europe from an Iberian refugium. Genome Research 15, 19-24.

Pettitt, P., 2005. Review of van Andel, T. \& W. Davies (eds.) 2003, Neanderthals and Modern Humans in the European Landscape during the Last Glaciation. The Holocene 15, 477-8.

Pettitt, P. \& P. Bahn, 2003. Current problems in dating Palaeolithic cave art: Candamo and Chauvet. Antiquity 77, 134-41.

Pettitt, P. \& A.W.G. Pike, 2001. Blind in a cloud of data: problems with the chronology of Neanderthal extinction and anatomically modern human expansion with comment by J.P. Bocquet-Appel and P.Y. Demars. Antiquity 75, 415-20.

Pettitt, P.B., W. Davies, C.S. Gamble \& M.B. Richards, 2003. Radiocarbon chronology: quantifying our confidence beyond two half-lives. Journal of Archaeological Science 30, 1685-93.
Press, W.H., S.A. Teukolsky, W.T. Vetterling \& B.P. Flannery, 1993. Numerical Recipes in C: the Art of Scientific Computing. Cambridge: Cambridge University Press.

Reich, D.E., M. Cargill, S. Bolk, J. Ireland, P.C. Sabeti, D.J. Richter, T. Lavery, R. Kouyoumjian, S.F. Farhadian, R. Ward \& E.S. Lander, 2001. Linkage disequilibrium in the human genome. Nature 411, 199-204.

Renfrew, C., 1987. Archaeology and Language: the Puzzle of Indo-European Origins. New York (NY): Cambridge University Press.

Renfrew, C., 1996. The sapient behaviour paradox: how to test for potential?, in Modelling the Early Human Mind, eds. P. Mellars \& K. Gibson. (McDonald Institute Monographs.) Cambridge: McDonald Institute for Archaeological Research, 11-14.

Renfrew, C., 2000. At the edge of knowability: towards a prehistory of languages. Cambridge Archaeological Journal 10(1), 7-34.

Renfrew, C., 2001. Symbol before concept: material engagement and the early development of society, in Archaeological Theory Today, ed. I. Hodder. London: Polity Press, 122-40.

Renfrew, C., 2003. Figuring it Out: What are We? Where do We Come From? The Parallel Visions of Artists and Archaeologists. London: Thames \& Hudson.

Renfrew, C. \& C. Scarre (eds.), 1998. Cognitive Storage and Material Culture: the Archaeology of Symbolic Storage. (McDonald Institute Monographs.) Cambridge: McDonald Institute for Archaeological Research.

Renfrew, C. \& E. Zubrow (eds.), 1994. The Ancient Mind: Elements of Cognitive Archaeology. Cambridge: Cambridge University Press.

Rensink, E., 1993. Moving into the North: Magdalenian Occupation and Exploitation of the Loess Landscapes of Northwestern Europe. Proefschrift: Leiden University.

Richards, M., V. Macaulay, E. Hickey, E. Vega, B. Sykes, V. Guida, C. Rengo, D. Sellitto, F. Cruciani, T. Kivisild, R. Villems, M. Thomas, S. Rychkov, O. Rychkov, Y. Rychkov, M. Gölge, D. Dimitrov, E. Hill, D. Bradley, V. Romano, F. Cali, G. Vona, A. Demaine, S. Papiha, C. Triantaphyllidis, G. Stefanescu, J. Hatina, M. Belledi, A. Di Rienzo, A. Novelletto, A. Oppenheim, S. Nørby, N. Al-Zaheri, S. Santachiara-Benerecetti, R. Scozzari, A. Torroni \& H.-J. Bandelt, 2000. Tracing European founder lineages in the Near Eastern mtDNA pool. American Journal of Human Genetics 67, 1251-76.

Rick, J., 1987. Dates as data: an examination of the Peruvian preceramic radiocarbon record. American Antiquity $52,55-73$.

Ripoll, S., 1994. The Paleolithic rock art of the Cueva de Ambrosio. INORA 7, 1-5.

Roberts, N., 2002. Did prehistoric landscape management retard the post-glacial spread of woodland southwest Asia? Antiquity 76, 1002-10.

Roque, C., P. Guibert, E. Vartanian, F. Bechtel, M. Schvoerer, C. Oberlin, J. Evin, N. Mercier, H. Valladas, J.P. Texier, J.P. Rigaud, F. Delpech, J.J. Cleyet Merle \& A. Turq, 2001. Une expérience de croisement de datations TL/ C14 sur la séquence solutréenne de Laugerie-Haute, 
Dordogne, in Datation, Actes des XXIe Rencontres Internationales d'Archéologie Historique, eds. J.N. Barrandon, P. Guibert \& M.V. Dir. Antibes: APDCA, 217-32.

Rootsi, S., C. Magri, T. Kivisild, G. Benuzzi, H. Help, M. Bermisheva, I. Kutuev, L. Barać, M. Peričić, O. Balanovsky, A. Pshenichnov, D. Dion, M. Grobei, L.A. Zhivotovsky, V. Battaglia, A. Achilli, N. Al-Zahery, J. Parik, R. King, C. Cinnioğlu, E. Khusnutdinova, P. Rudan, E. Balanovska, W. Scheffrahn, M. Simonescu, A. Brehm, R. Goncalves, A. Rosa, J.-P. Moisan, A. Chaventre, V. Ferak, S. Füredi, P.J. Oefner, P. Shen, L. Beckman, I. Mikerezi, R. Terzić, D. Primorac, A. Cambon-Thomsen, A. Krumina, A. Torroni, P.A. Underhill, A. Santachiara-Benerecetti, R. Villems \& O. Semino, 2004. Phylogeography of Y-chromosome haplogroup I reveals distinct domains of prehistoric gene flow in Europe. American Journal of Human Genetics 75, 128-37.

Ross, C.A., 2001. Radiocarbon Evidence for the Late Upper Palaeolithic Recolonization of Central Europe. Unpublished PhD Dissertation, University of Southampton.

Runciman, W.G., 2005. Stone age sociology. Journal of the Royal Anthropolgical Institute 11, 129-42.

Sanchidrián, J.L., A. Márquez, H. Valladas \& N. Tisnerat, 2001. Direct dates for Andalusian rock art. INORA 29, 15-19.

Schwendler, R., 2004. Hunter-gatherer Social Interactions in Magdalenian Western Europe. Unpublished PhD disseration, University of New Mexico.

Searls, D.B., 2003. Trees of life and of language. Nature 426, 391-2.

Semino, O., G. Passarino, P.J. Oefner, A.A. Lin, S. Arbuzova, L.E. Beckman, G. De Benedictis, P. Francalacci, A. Kouvatsl, S. Limborska, M. Marcikiae, A. Mika, B. Mika, D. Primorac, A.S. Santachiara-Benerecetti, L.L. CavalliSforza \& P.A. Underhill, 2000. The genetic legacy of Paleolithic Homo sapiens sapiens in extant Europeans: a Y-chromosome perspective. Science 290, 1155-9.

Shennan, S., 2001. Demography and cultural innovation: a model and its implications for the emergence of modern human culture. Cambridge Archaeological Journal 11(1), 5-16.

Shennan, S., 2002. Genes, Memes and Human History: Darwinian Archaeology and Cultural Evolution. London: Thames \& Hudson.

Sherratt, A., 1997. Economy and Society in Prehistoric Europe: Changing Perspectives. Edinburgh: Edinburgh University Press.

Sims-Williams, P., 1998. Genetics, linguistics and prehistory: thinking big and thinking straight. Antiquity 72, 505-27.

Soffer, O., 1987. Upper Palaeolithic connubia, refugia, and the archaeological record from eastern Europe, in The Pleistocene Old World: Regional Perspectives, ed. O. Soffer. New York (NY): Plenum, 333-48.

Soffer, O. \& C.S. Gamble (eds.), 1990. The World at 18000 вр, vol. 1: High Latitudes. London: Unwin Hyman.

Sokal, R.R., N.L. Oden \& J. Walker, 1989. Genetic distances among language families in Europe. American Journal of Physical Anthropology 76, 337-61.

Steele, J., J. Adams \& T. J. Sluckin, 1998. Modelling palaeoindian dispersals. World Archaeology 30, 286-305.

Stewart, J.B., 2003. Comment on 'buffered tree population changes in a quaternary refugium: evolutionary implications'. Science 299, 825.

Straus, L.G., 1977. Of deerslayers and mountain men: Paleolithic faunal exploitation in Cantabrian Spain, in For Theory Building in Archaeology, ed. L.R. Binford. New York (NY): Academic Press, 41-76.

Straus, L.G., 1991. Human geography of the late Upper Paleolithic in western Europe. Journal of Anthropological Research 47, 259-78.

Straus, L.G., 1992. Iberia before the Iberians. Albuquerque (NM): University of New Mexico Press.

Straus, L.G., 2000a. Coming out of the cold: western Europe in Dryas I and beyond, in Regional Approaches to Adaptation in Late Pleistocene Western Europe, eds. G.L. Peterkin \& H.A. Price. (British Archaeological Reports International Series 896.) Oxford: BAR, 191-203.

Straus, L.G., 2000b. A quarter-century of research on the Solutrean of Vasco-Cantabria, Iberia and beyond. Journal of Anthroplogical Research 56, 39-58.

Straus, L.G. \& G.A. Clark, 1997. La grotte de la Riera (Asturies) et la question du Solutréen cantabrique (et ibérique). Bulletin de la Société Préhistorique Française 97, 129-40.

Straus, L.G., B.V. Eriksen, J.M. Erlandson \& D.R. Yesner (eds.), 1996. Humans at the End of the Ice Age: the Archaeology of the Pleistocene-Holocene Transition. New York (NY): Plenum.

Straus, L.G., M. Otte, A. Gautier, P. Haesaerts, I. López, P. Lacroix, A. Martinez, R. Miller, J. Orphal \& A. Stutz, 1997. Late Quaternary prehistoric investigation in southern Belgium. Préhistoire Européenne 11, 145-83.

Straus, L.G., N. Bicho \& A. Winegardner, 2000a. The Upper Palaeolithic settlement of Iberia: first-generation maps. Antiquity 74, 553-66.

Straus, L.G., N. Bicho \& A. Winegardner, 2000b. Mapping the Upper Paleolithic regions of Iberia. Journal of Iberian Archaeology 2, 7-42.

Street, M. \& T. Terberger, 1999. The last Pleniglacial and the human settlement of central Europe: new information from the Rhineland site of Wiesbaden-Igstadt. Antiquity 73, 259-72.

Street, M. \& T. Terberger, 2000. The German Upper Palaeolithic 35,000-15,000 вр. New dates and insights with emphasis on the Rhineland, in Hunters of the Golden Age: Papers from the European Science Foundation Colloquium at Pavlov, eds. W. Roebroeks, M. Mussi, J. Svoboda \& K. Fennema. Leiden: University of Leiden, 281-98.

Street, M., M. Baales, E. Cziesla, S. Hartz, M. Heinen, O. Jöris, I. Koch, C. Pasda, T. Terberger \& J. Vollbrecht, 2001. Final Paleolithic and Mesolithic research in reunified Germany. Journal of World Prehistory 15, 365-453.

Tchernov, E., 1992. Dispersal, a suggestion for a common usage of this term, in Mammalian Migration and Dispersal Events in the European Quaternary, vol. 153, eds. 
W. v. Koenigswald \& L.Werdelin. Frankfurt: Courier Forschungsinstitut Senckenberg, 21-5.

Terberger, T. \& M. Street, 2002. Hiatus or continuity? New results for the question of pleniglacial settlement in central Europe. Antiquity 76, 691-8.

Thévenin, A., 1995. Le peuplement de l'Est de la France du Tardiglaciaire au début du Postglaciaire, in Épipaléolithique et Mésolithique entre Seine et Rhin, Table Ronde d'Ancerville 1989, ed. A. Thévenin. Paris: Série Archéologie 41, 213-73.

Torroni, A., H.-J. Bandelt, L. D’Urbano, P. Lahermo, P. Moral, D. Sellitto, C. Rengo, P. Forster, M.L. Savontaus, B. Bonné-Tamir \& R. Scozzari, 1998. MtDNA analysis reveals a major late Palaeolithic population expansion from southwestern to northeastern Europe. American Journal of Human Genetics 62, 1137-52.

Torroni, A., H.-J. Bandelt, V. Macaulay, M. Richards, F. Cruciani, C. Rengo, V. Martinez-Cabrera, R. Villems, T. Kivisild, E. Metspalu, J. Parik, H.-V. Tolk, K. Tambets, P. Forster, B. Karger, P. Francalacci, P. Rudan, O. Rickards, M.-L. Savontaus, K. Huoponen, V. Laitinen, S. Koivumäki, B. Sykes, E. Hickey, A. Novelletto, P. Moral, D. Sellitto, A.S. Santachiara-Benerecetti, O. Semino \& R. Scozzari, 2001. A signal, from human mtDNA, of postglacial recolonization in Europe. American Journal Human Genetics 69, 844-52.

Trinkaus, E., 1990. Cladistics and the hominid fossil record. American Journal of Physical Anthropology 83, 1-11.

van Andel, T.H., 2005 in press. The ownership of time: officially approved ${ }^{14} \mathrm{C}$ calibration or freedom of choice. Antiquity 79 (Sept. 2005).

van Andel, T.H. \& W. Davies (eds.), 2003. Neanderthals and Modern Humans in the European Landscape During the Last Glaciation. (McDonald Institute Monographs.) Cambridge: McDonald Institute for Archaeological Research.

van Andel, T.H. \& C. Runnels, 1995. The earliest farmers in Europe. Antiquity 69, 481-500.

van Andel, T.H., W. Davies, B. Weninger \& O. Jöris, 2003. Archaeological dates as proxies for the spatial and temporal human presence in Europe: a discourse on the method, in Neanderthals and Modern Humans in the European Landscape during the Last Glaciation, eds. T. van Andel \& W. Davies. (McDonald Institute Monographs.) Cambridge: McDonald Institute for Archaeological Research, 21-9.

Vita-Finzi, C. \& E.S. Higgs, 1970. Prehistoric economy in the Mount Carmel area of Palestine, site catchment analysis. Proceedings of the Prehistoric Society 36, 1-37.

Vrba, E.S. 1988. Late Pliocene climatic events and hominid evolution, in Evolutionary History of the 'Robust' Australopithecines, ed. F.E. Grine. New York (NY): Aldine de Gruyter, 405-26.

Walker, M.J., S. Björck, J.J. Lowe, L.C. Cwynar, S. Johnsen, K.L. Knudsen, B. Wohlfarth \& INTIMATE group. 1999. Isotopic 'events' in the GRIP ice core: a stratotype for the Late Pleistocene. Quaternary Scence Reviews
$18,1143-50$.

Walker, M.J., G.R. Coope, C. Sheldrick, C.S.M. Turney, J.J. Lowe, S.P.E. Blockley \& D.D. Harkness, 2003. Devensian Late Glacial environmental changes in Britain: a multi-proxy environmental record from Llanild, South Wales, UK. Quaternary Scence Reviews 22, 475-520.

Weninger, B. \& O. Jöris, 2000. 'CALPAL', 1.10 .00 edition. Cologne: Radiocarbon Laboratory Institut Fur Urgeschichte Und Fruhgeschichte Weyertal 125 D-50923. http: / / www.calpal.de.

Weninger, B. \& O. Jöris, 2004. CalPal Radiocarbon calibration package (7 July 2004 version). Cologne: Radiocarbon Laboratory, Institut für Urgeschichte und Frügeschichte, Weyertal 125, D-50923. http:/ / www.calpal. de/calpal/index.htm.

Willis, K.J. \& R.J. Whittaker, 2000. The refugial debate. Science 287, 1406-7.

Willis, K.J., K.D. Bennett \& D. Walker (eds.), 2004. The evolutionary legacy of the Ice Ages, vol. 359. Philosophical Transactions of the Royal Society B (Biological Sciences) 359(1442), 155-303.

Willis, K.J., E. Rudner \& P. Sumegi, 2000. The full-glacial forests of central and southeastern Europe. Quaternary Research 53, 203-13.

Wobst, M., 1974. The archaeology of Band Society: some unanswered questions. Memoir of the Society for American Archaeology 29, v-xiii.

Wynn, T., 1993. Layers of thinking in tool behaviour, in Tools, Language and Cognition in Human Evolution, eds. K. Gibson \& T. Ingold. Cambridge: Cambridge University Press, 389-406.

Wynn, T. \& F.L. Coolidge, 2004. The expert Neanderthal mind. Journal of Human Evolution 20, 1-21.

Zerjal, T., L. Beckman, G. Beckman, A.-V. Mikelsaar, A. Kruminar, V. Kucinskas, M.E. Hurles \& C. Tyler-Smith, 1991. Geographical, linguistic, and cultural influences on genetic diversity: Y-chromosomal distribution in northern European populations. Molecular Biology Evolution 2001 18, 1077-87.

Zilhão, J., 1997. Arte Rupestre e Pré-História do Vale do Côa. Lisbon: Ministério da Cultura.

Zvelebil, M. (ed.), 1986. Hunters in Transition: Postglacial Adaptations in the Temperate Regions of the Old World. Cambridge: Cambridge University Press.

Zvelebil, M., 1996. Farmers our ancestors and the identity of Europe, in Cutlural Identity and Archaeology: the Construction of European Communities, eds. P.M. GravesBrown, S. Jones \& C. Gamble. London: Routledge, 145-66.

Zvelebil, M., 2001. Revisiting Indreko's culture historical model: 'Origin and are of settlement of the FinnoUgrian peoples'. Trames 5(55/50), 26-47.

Zvelebil, M., 2002. Indo-European dispersals and the agricultural transition in northern Europe: culture, genes and language, in The Roots of Peoples and Languages of Northern Eurasia, vol. IV, ed. K. Julku. Oulu: Societas Historiae Fenno-Ugricae, 318-43. 

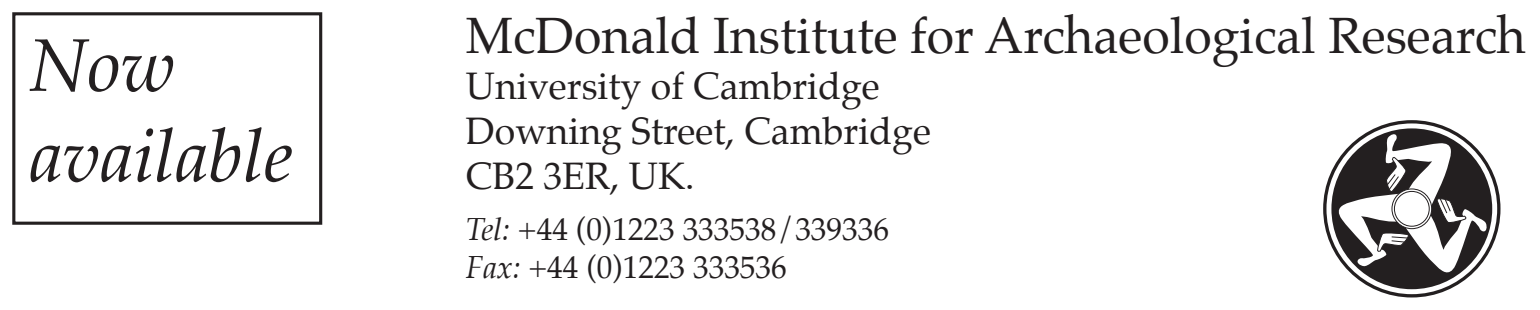

Title: Dwelling among the monuments: the Neolithic village of Barnhouse, Maeshowe passage grave and surrounding monuments at Stenness, Orkney

Editor: Colin Richards

Series: McDonald Institute Monographs

Classifications: Archaeology; Neolithic Orkney; Barnhouse

Binding: Cloth

Size: $286 \times 220 \mathrm{~mm}$

Pages: xxii+397 pp.; 399 illustrations, 29 tables

ISBN: 1-902937-18-X hardback

ISSN: $1363-1349$

Price: $£ 40$; US\$80

Publication date: March 30, 2005

Distributor: Oxbow Books, Park End Place, Oxford, OX1 1HN, UK. Tel: (01865) 241249;

www.oxbowbooks.com - or -

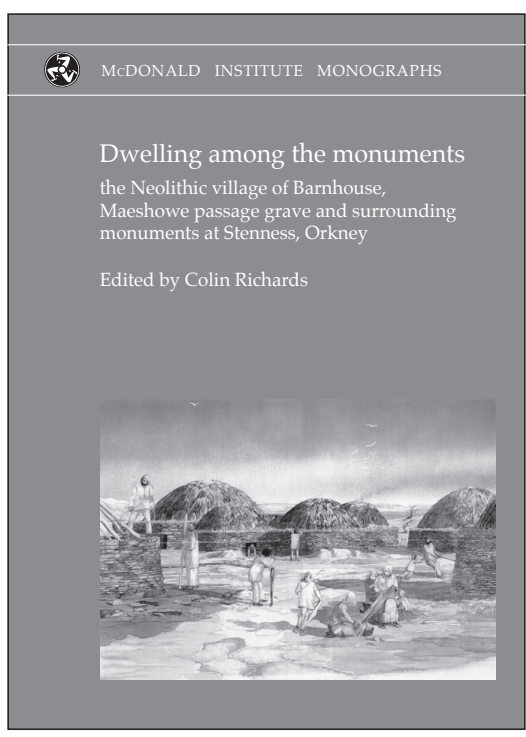

David Brown Book Co., P.O. Box 511, Oakville, CT 06779, USA.

Tel: 860-945-9329; Fax: 860-945-9468

$\mathrm{T}$ his volume provides an exciting account of the lives of the inhabitants of the village of Barnhouse, a Late Neolithic settlement complex in Orkney. The excavation of Barnhouse between 1986 and 1993 in fact constitutes the largest investigation of a Neolithic settlement in northern Britain since Gordon Childe examined the nearby village of Skara Brae in the 1920s. It consequently provides an ideal opportunity to reconsider architectural representation, the social construction of identity, and social and ritual practices within a Late Neolithic community and beyond. The inhabitants of Barnhouse lived within one of the most spectacular monumental landscapes of the British Neolithic, and this volume also describes smaller-scale excavations at the nearby passage grave of Maeshowe and at the Stone of Odin. The results of these investigations provide the basis for an interpretative account of the habitation and construction of this monumental landscape over a fivehundred-year period of Orcadian prehistory (c. 3200-2700 BC). In its form and conception, Dwelling among the monuments marks a departure from standard archaeological excavation monographs: while containing the customary descriptive accounts and the full suite of specialist reports, it employs archaeological evidence to capture the social dimensions of life within a village and its associated monuments during the Late Neolithic.

\section{EDITOR:}

Colin Richards, School of Arts, Histories \& Cultures, The University of Manchester, Oxford Road, Manchester, M13 9PL, UK.

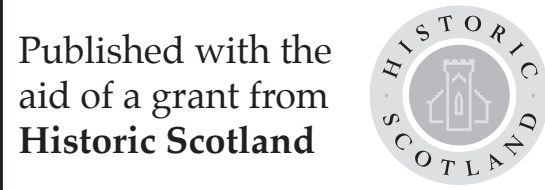

For more information please contact: Liz Farmar, McDonald Institute for Archaeological Research, Downing Street, Cambridge, CB2 3ER, UK; eaf22@cam.ac.uk. 